Département de sciences économiques

2005-19

\title{
Why Have Aggregate Skilled Hours Become So Cyclical Since the Mid-1980's?
}

CASTRO, RUi

COEN-PIRANI, Daniele 


\section{Département de sciences économiques}

Université de Montréal

Faculté des arts et des sciences

C.P. 6128, succursale Centre-Ville

Montréal (Québec) H3C 3J7

Canada

http://www.sceco.umontreal.ca

SCECO-information@UMontreal.CA

Téléphone : (514) 343-6539

Télécopieur : (514) 343-7221

Ce cahier a également été publié par le Centre interuniversitaire de recherche en économie quantitative (CIREQ) sous le numéro 24-2005.

This working paper was also published by the Center for Interuniversity Research in Quantitative Economics (CIREQ), under number 24-2005.

ISSN 0709-9231 


\title{
Why Have Aggregate Skilled Hours Become So Cyclical Since the Mid-1980's?*
}

\author{
Rui Castro ${ }^{\dagger} \quad$ Daniele Coen-Pirani ${ }^{\ddagger}$
}

First Version: June 2003

This Version: June 2005

\begin{abstract}
This paper documents and discusses a dramatic change in the cyclical behavior of aggregate hours worked by individuals with a college degree (skilled workers) since the mid-1980's. Using the CPS outgoing rotation data set for the period 1979:1-2003:4, we find that the volatility of aggregate skilled hours relative to the volatility of GDP has nearly tripled since 1984. In contrast, the cyclical properties of unskilled hours have remained essentially unchanged. We evaluate the extent to which a simple supply/demand model for skilled and unskilled labor with capital-skill complementarity in production can help explain this stylized fact. Within this framework, we identify three effects which would lead to an increase in the relative volatility of skilled hours: (i) a reduction in the degree of capital-skill complementarity, (ii) a reduction in the absolute volatility of GDP (and unskilled hours), and (iii) an increase in the level of capital equipment relative to skilled labor. We provide empirical evidence in support of each of these effects. Our conclusion is that these three mechanisms can jointly explain about sixty percent of the observed increase in the relative volatility of skilled labor. The reduction in the degree of capital-skill complementarity contributes the most to this result.
\end{abstract}

Keywords: Macroeconomics, Business Cycles, Volatility, Skilled Hours, Skill Premium, CapitalSkill Complementarity.

JEL Codes: E24, E32, J24, J31.

*We thank Paul Beaudry, Jenny Hunt, Per Krusell, José-Victor Ríos-Rull, Scott Schuh, Fallaw Sowell, and Gianluca Violante for helpful conversations and comments, as well as seminar attendants at Texas A\&M, Rice University, Dallas Fed, University of Pennsylvania, University of Texas at Austin, Carnegie Mellon (lunch seminar), New York University, Université Laval, 2005 Midwest Macro Meetings in Iowa City, 2004 Canadian Macro Study Group in Montréal, 2004 CEA Meeting in Toronto, 2003 Rochester Wegmans conference, and 2003 SED Meeting in Paris, for helpful suggestions on earlier drafts of this paper. Thanks to Gianluca Violante for providing us with the data for capital equipment. We thank Timothée Picarello and Maria Julia Bocco for excellent research assistance. Financial support from the W.E. Upjohn Institute for Employment Research is gratefully acknowledged. The usual disclaimer applies.

${ }^{\dagger}$ Department of Economics and CIREQ, Université de Montréal. Email: rui.castro@umontreal.ca. Web: http://www.fas.montreal.ca/sceco/castroru

${ }^{\ddagger}$ Tepper School of Business, Carnegie Mellon University. E-mail: coenp@andrew.cmu.edu. Web: http://www.andrew.cmu.edu/user/coenp/web 


\section{Introduction}

In recent years economists have dedicated considerable attention to the study of the causes and implications of the sustained increase in the skill premium in the U.S. starting from the late 1970's. ${ }^{1}$ This literature has provided interesting insights on the economic forces driving the relative demand for skilled workers and their relative wages over the course of the last 25-30 years.

It is fair to say that economists have, instead, paid considerably less attention to the analysis of the cyclical behavior of aggregate employment and wages of skilled and unskilled workers in the same sample period. Skilled labor has been traditionally thought of as being relatively insulated from business cycle fluctuations, with most variations in aggregate hours of work being accounted for by changes in unskilled employment (Kydland (1984) and Keane and Prasad (1993)). In this paper we document that this has not been the case in the last twenty years. Since the mid1980's, aggregate hours worked by individuals with a college degree ("skilled") have become as procyclical as, and slightly more volatile than, the hours worked by individuals without a college degree ("unskilled"). The cyclical properties of the latter have, instead, remained roughly constant relative to aggregate output over our sample period. This dramatic increase in the cyclicality of skilled labor has received some attention in the popular press, but has not been extensively documented, quantified or formally discussed by academics so far. ${ }^{2}$ In this paper we first document and then try to formally explain these trends. A central feature of our analysis is that it is tightly connected to the extensive literature on the low frequency dynamics of the skill premium.

Empirical Analysis. We first use the Current Population Survey (CPS)'s Merged Outgoing Rotation Groups to construct quarterly measures of the quantity and price of hours worked by college educated and non-college educated workers for the sample period 1979:1-2003:4. To compute the quantity and price of labor of each skill group, hours worked by different individuals are aggregated controlling for composition effects. These data reveal a striking change in the cyclical

\footnotetext{
${ }^{1}$ For a recent review of this literature, see Acemoglu (2002).

${ }^{2}$ See, for example, the 1996 article by Paul Krugman and the 2002 article by Alan Krueger in the New York Times. The former writes that: "As economists quickly pointed out, the rate at which Americans were losing jobs in the 90s was not especially high by historical standards. Why, then, did downsizing suddenly become news? Because for the first time white-collar, college-educated workers were being fired in large numbers, even while skilled machinists and other blue-collar workers were in high demand. This should have been a clear signal that the days of ever-rising wage premia for people with higher education were over, but somehow nobody noticed." Below we review the related empirical literature.
} 
behavior of aggregate hours worked by skilled individuals around 1984. Whereas aggregate hours for unskilled workers follows closely the behavior of real Gross Domestic Product (GDP) and becomes substantially less volatile after 1984, the corresponding series for skilled workers becomes slightly more volatile. This motivates us to split the sample in 1984 and to consider the two sub-periods separately.

In the 1979:1-1983:4 sub-period, detrended aggregate hours worked by skilled individuals are not very volatile, with a standard deviation relative to GDP of 0.37. Instead, the unskilled labor input is roughly as volatile as GDP, with a relative standard deviation of 0.97 .

In the 1984:1-2003:4 sub-period, instead, the relative volatility of skilled hours increases to 1.04, a figure that actually exceeds the corresponding one for unskilled hours (0.90). This pattern is dominated by an increase in the relative volatility of skilled employment rather than average hours per employed worker. The behavior of unskilled hours relative to GDP remains basically the same as in the first sub-period. In contrast to the change in the behavior of skilled hours, the skill premium has remained essentially acyclical and not very volatile relative to GDP throughout the entire sample period.

Theory and Empirical Implementation. Our second goal is to try to qualitatively and quantitatively explain the increase in the cyclical volatility of skilled hours. For this purpose, we adopt a simple relative demand/supply framework. On the demand side, we consider the problem of a competitive representative firm optimally choosing its labor inputs and capital stocks for given input prices, technology, and business cycle shocks. Consistently with recent empirical literature on the low-frequency behavior of the skill premium (see e.g. Krusell, Ohanian, Ríos-Rull, and Violante (2000)), we postulate that the production function exhibits capital-skill complementarity. On the supply side, and in line with the empirical evidence, we assume preferences that yield an infinitely elastic relative supply of skilled labor, and hence a constant skill premium at the cyclical frequency.

In equilibrium, capital-skill complementarity implies that skilled hours are cyclically less volatile than unskilled hours. To see this, consider for example a recession. In a recession, demand for skilled and unskilled hours drops. However, given that the stock of capital equipment changes slowly at high frequencies, capital-skill complementarity in production increases the relative demand for skilled hours, leading to a smaller reduction in the quantity of this type of labor input. Oi (1962) 
and Rosen (1968) call this mechanism the "substitution hypothesis".

Our main hypothesis is that there has been a structural decrease in the degree of capital-skill complementarity that occurred sometime between the mid to late 1980's. To make it operational, we calibrate the parameters of the model to account for the slowdown in the growth rate of the skilled premium since the late 1980's. The latter occurred despite the dramatic increase in the growth rate of the stock of capital equipment in the same period.

In addition, we show that the capital-skill complementarity production structure also implies that the relative volatility of skilled hours is inversely related to the absolute volatility of GDP (and unskilled labor) and positively related to the level of the stock of capital equipment relative to skilled labor. We also find evidence for these two channels and evaluate their contribution to the higher volatility of skilled hours.

Results. The mechanisms discussed above jointly account for about sixty percent of the increase in the relative volatility of skilled hours. The main effect, from a quantitative point of view, comes from the reduction in the degree of capital-skill complementarity, followed by the lower volatility of GDP and unskilled labor.

Related Literature. This paper is related to several literatures. Our stylized facts for the 1979-1984 period confirm the findings from previous work. Using microdata spanning the 1970s and early 1980s, Kydland (1984) and Keane and Prasad (1993) also provide evidence that employment of skilled workers is less cyclical than its counterpart for unskilled workers, and Keane and Prasad (1993) also find the skill premium to be acyclical. ${ }^{3}$ In Section 6 we ask whether this pattern extends back to the early 1960's. Using annual data from the March CPS, we instead document that aggregate skilled employment has been relatively acyclical only in the 1976-1983 period. In the 1963-1975 period, the volatilities of skilled and unskilled labor were not significantly different. We then discuss the implications of this finding for our main hypothesis.

A few formal models have attempted to rationalize the lower cyclicality of skilled hours. Kydland (1984) and Prasad (1996) extend the representative agent real business cycle model to allow for skilled and unskilled workers, but rely on exogenous mechanisms to make skilled labor more volatile.

\footnotetext{
${ }^{3}$ Previously, Reder (1955) had found some evidence that the skill premium was countercyclical in the 1930's and 1940's, but his study did not control for composition effects.
} 
Young (2003) and Lindquist (2004) consider calibrated general equilibrium models with capitalskill complementarity in production, with the goal of explaining the acyclical behavior of the skill premium in the last 25 years. They analyze the same data as we do, but do not split the sample and therefore fail to detect the dramatic increase in the volatility of skilled hours since $1984 .^{4}$

A growing literature, reviewed by Stock and Watson (2002), has documented and discussed the reduction in the volatility of GDP and aggregate hours that occurred around 1984. As far as we are aware, we are the first to provide a comprehensive documentation of the change in the cyclical behavior of skilled and unskilled hours that occurred also in the mid-1980's. This decomposition is interesting because, while unskilled hours follow closely the behavior of GDP, skilled hours display a very different pattern. Farber (2005) provides some independent evidence consistent with our findings using the Displaced Workers Survey supplements of the CPS. ${ }^{5}$

Finally, this paper is related to the recent literature on the low frequency dynamics of the skill premium (see Acemoglu (2002) for a review). Katz and Murphy (1992) and Krusell, Ohanian, Ríos-Rull, and Violante (2000), among others, have argued that the decline of the skill premium in the 1970's and its increase in the early 1980's are consistent with a simple supply/demand view of the labor market. ${ }^{6}$ Our formal analysis is based on the capital-skill complementarity framework developed by Krusell, Ohanian, Ríos-Rull, and Violante (2000). We use the long-run trends in the skill premium and the production inputs to calibrate the key parameters of the model, and then evaluate its implications for the business cycle. Importantly, like Card and DiNardo (2002) and Beaudry and Green (2002), we find strong evidence of a slowdown in the demand for college educated workers in the 1990's. In calibrating the model, we capture this slowdown by allowing for a reduction in the degree of capital-skill complementarity since the late 1980's.

\footnotetext{
${ }^{4}$ Both papers focus more on the behavior of prices (the skill premium) than on allocations (relative hours worked). When focusing on the entire sample 1979:1-2003:4 we find that our empirical results concerning the correlation of the skill premium with output are similar to the ones reported in Young (2003) and Lindquist (2004). However, contrary to Lindquist (2004), and similarly to Young (2003), we find that the skill premium is significantly less volatile than output. This discrepancy might be explained by the fact that Lindquist (2004) defines skilled (unskilled) wages as the average of hourly wages across skilled (unskilled) workers. Instead, we define skilled wages as the ratio of total weekly earnings by skilled workers and their total hours. The difference between these two approaches is that the former weights all individual wages equally while the latter uses individuals' relative hours as weights.

${ }^{5}$ It is important to notice that, differently from Farber, who focuses on involuntary separations between workers and employers, our analysis is centered around the behavior of aggregate hours worked by each skill group.

${ }^{6}$ These two papers differ in one important dimension. Katz and Murphy (1992) argue that the dynamics of the skill premium in the period 1963-1987 can be explained by variations in the relative supply of skilled workers combined with a constant rate of growth of skill-biased technological change. Krusell, Ohanian, Ríos-Rull, and Violante (2000), instead, argue that the acceleration in the growth rate of capital equipment since the late 1970's, plays a major role in accounting for the increase in the skill premium in the 1980's.
} 
The remainder of the paper is organized as follows. In Section 2 we present and discuss the stylized facts about the behavior of the skilled and unskilled labor inputs and their relative price that are the object of our empirical analysis. In Section 3, we rule out explanations of our empirical findings based on composition effects. In Section 4 we discuss our hypothesis from a qualitative point of view. Section 5 presents the quantitative results. Section 6 presents some empirical evidence for the pre-1979 period. Section 7 discusses alternative explanations for the higher volatility of skilled labor. Section 8 concludes. Appendix A contains additional information regarding the data, and Appendix B looks at Canadian evidence.

\section{Empirical Analysis}

Our goal in this section is to document the business cycle dynamics of total hours, employment, weekly working hours per employed worker, and relative wages of skilled and unskilled individuals. An individual is "skilled" if he/she has obtained at least a four-year college degree. In order to construct "skilled" and "unskilled" aggregates for these variables we take an efficiency units approach, analogous to that of Katz and Murphy (1992) and Krusell, Ohanian, Ríos-Rull, and Violante (2000).

\subsection{Data}

The main data set we use is the Merged Outgoing Rotation Groups (MORG) extracts from 288 Monthly Current Population Surveys (CPS), prepared by the NBER and covering the period from 1979 through 2003. ${ }^{7}$ The MORG represents the only comprehensive set of quarterly data with information regarding individual weekly hours and, especially, wages. One drawback is that these data are available only since 1979, leaving us with a relatively short sub-sample before the 1984 break date. The latter, however, includes one of the deepest recessions after WWII, the 1981-82 recession. In Section 6 we complement our analysis with yearly March CPS data on employment, which allows us to extend the sample period to 1963-2002. This pre-1979 evidence is important because it allows us to test some of the implications of our main hypothesis regarding the structural decline in the degree of capitak-skill complementarity and distinguish them from alternative

\footnotetext{
${ }^{7}$ More details on the data and the variables are provided in Appendix A.
} 
explanations. We postpone the discussion of these findings to Sections 6 and 7 .

Each monthly sample contains about 30,000 individuals which are associated with a sample weight and are representative of the U.S. population. In what follows we always use these weights to aggregate individual observations. We organize the data by quarters, ending up with 100 observations for the variables of interest. These 100 quarters include four NBER-defined recessions (1980:1-1980:3, 1981:3-1982:4, 1990:3-1991:1 and 2001:1-2001:4).

For each quarter, we restrict attention to individuals in the labor force between 16 and 65 years of age that are not self-employed, to concentrate on paid earnings. After applying some standard sample selection criteria to deal with missing observations and coding errors we end up, for each quarter, with a cross-section of about 45,000 representative individuals, of which, on average, about 10,000 hold at least a college degree.

The variables we use to construct measures of employment and hours of work for skilled and unskilled workers are: employment status, usual weekly earnings (inclusive of overtime, tips and commissions), usual weekly hours worked, and a series of demographic variables such as age, sex, race and years of education.

Weekly earnings are top-coded in the CPS. The top-code was revised twice during the sample, at the end of 1988 and at the end of 1997. We imputed top-coded earnings by multiplying every top-coded value in the sample by 1.3. This adjustment factor ensures that average earnings in the top decile remain constant from December 1988 to January 1989 (when only a very small number of observations is top-coded). It turns out that the same adjustment factor works for 1997. For each quarter, real weekly earnings are computed by deflating nominal weekly earnings by the Consumer Price Index (CPI). Real hourly wages are computed as real weekly earnings divided by usual weekly hours.

The variables of interest are defined in more detail as follows.

Employment. Aggregate employment for skilled (unskilled) individuals in a given quarter is just the sum of skilled (unskilled) individuals, weighted by their sampling weight, who report to be employed in that period. Aggregate skilled employment grew over the sample period at the average rate of 3.3 percent per year, against an yearly growth rate of 0.8 percent of unskilled employment. Thus, the skilled share of aggregate employment went from about 18 percent 
in 1979:1 to approximately 29 percent in 2003:4.

Total Hours. To construct a measure of total hours worked by skilled (unskilled) individuals in a given quarter we adopt an efficiency units approach. ${ }^{8}$ This amounts to using some timeinvariant measure of individuals' hourly wages as weights when aggregating the hours worked by different individuals. When looking at business cycles, one advantage of this procedure is that it controls for composition effects. For example, if labor force quality is countercyclical, then a simple aggregation of hours across workers is likely to introduce a countercyclical bias in the measure of the real wage and exaggerate the volatility of hours over the cycle. ${ }^{9}$ We first partition the sample into 240 demographic groups. Demographic groups are constructed using information on individuals' sex, age, race and education. First, for each quarter and for each demographic group in our partition, we compute total weekly hours worked by individuals in that group and their associated total earnings by summing up the individual data. This amounts to assuming that individuals in each demographic group are perfect substitutes. We then divide total weekly earnings by total hours to obtain a measure of the hourly wage rate for that demographic group. A group's average hourly wage rate across all quarters is then used, together with its sampling weight, to aggregate hours of work across demographic groups. Total hours for skilled (unskilled) workers in a quarter are then defined as the weighted sum of total hours worked by demographic groups composed by skilled (unskilled) individuals. These two series are reported in Figure 1. This figure documents an increase in total hours throughout the sample period, at a significantly higher pace for skilled workers. As suggested above, the main driving force was an increase in the relative employment of skilled workers.

Average Weekly Working Hours. This variable is defined as Total Hours divided by Employment.

Hourly Wage. To define the hourly wage for skilled (unskilled) individuals we divide the sum of

\footnotetext{
${ }^{8}$ This is a point of departure of our empirical analysis from Young (2003) and Lindquist (2004), who do not control for cyclical changes in the demographic composition of skilled and unskilled employment. Also, Young's (2003) reported statistics computed using the MORG data (Table 1, page 24) suggest that he is focusing on average hours worked by employed individuals, rather than total hours (which are significantly more volatile).

${ }^{9}$ Rather than focusing on hours in efficiency units as a way to overcome the aggregation bias, several papers in the literature have alternatively exploited the panel dimension of the data, in order to control for worker characteristics - see Bils (1985), Solon, Barski, and Parker (1994) and Keane and Prasad (1993). For papers that have also used an efficiency units approach see Hansen (1993), Kydland and Prescott (1993) and Bowlus, Liu, and Robinson (2002).
} 


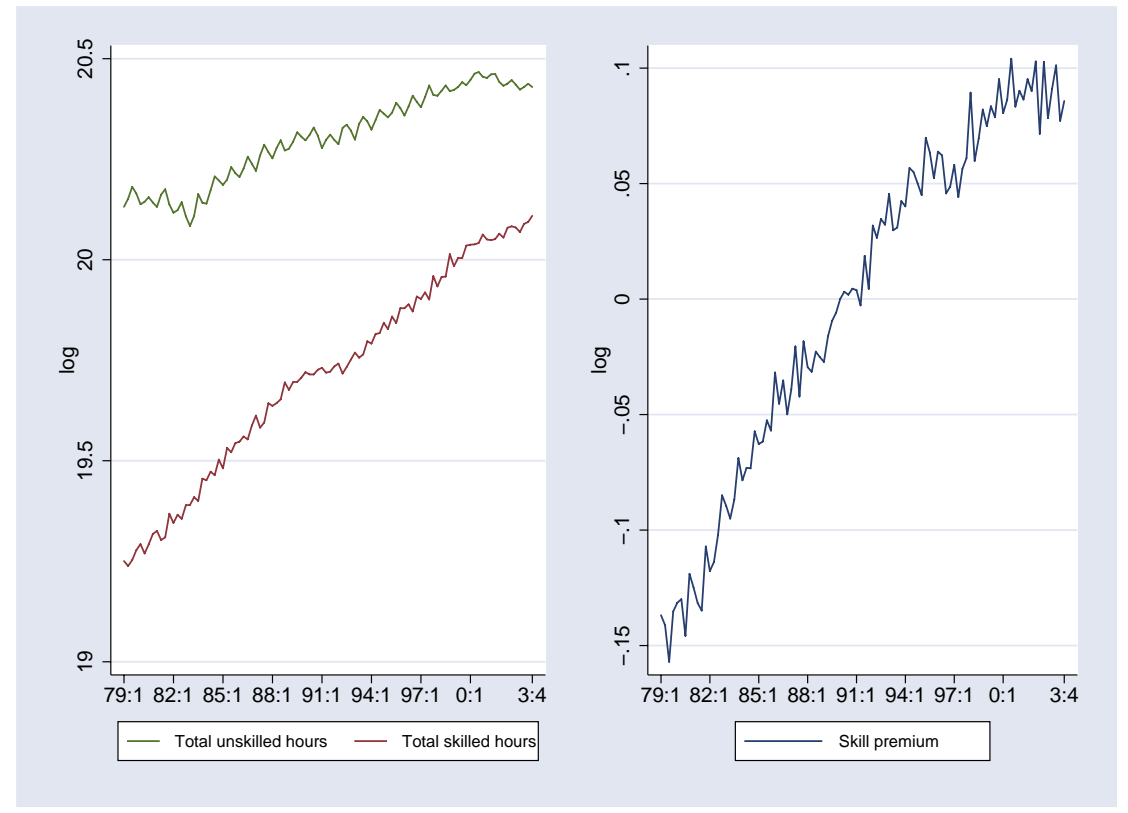

Figure 1: Total Hours and Skill Premium

weekly earnings across the appropriate demographic groups by our measure of total hours.

Skill Premium. The skill premium is defined as the ratio of hourly wages of skilled and unskilled workers. It is also represented in Figure 1. The figure documents a steady increase in the skill premium in the last two decades, 22 percent between 1979:1 and 2003:4, with a slower growth rate in the 1990's.

\section{$2.2 \quad$ Stylized Facts}

In what follows we are interested in the behavior of the quantity and price variables described above at the business cycle frequency. The raw series of all the variables considered in this section, like the ones in Figure 1, typically display a trend, seasonal cycles, and fluctuations with higher frequencies than standard business cycles. In order to deseasonalize the series we use the Census Bureau's seasonal adjustment program, X12. In order to smooth the high frequency variations in the data, we applied a centered five quarters moving average to the seasonally adjusted series. ${ }^{10}$

\footnotetext{
${ }^{10}$ This high frequency noise is likely due to measurement error. In fact, it becomes more significant for more disaggregated time-series, such as the ones underlying Tables 3 and 5, which are based upon a smaller number of observations. Filtering away the high frequency fluctuations in the data does not significantly affect the stylized facts emphasized in this section. The tables presented in this section, obtained using deseasonalized but unfiltered data, are available from the authors upon request.
} 


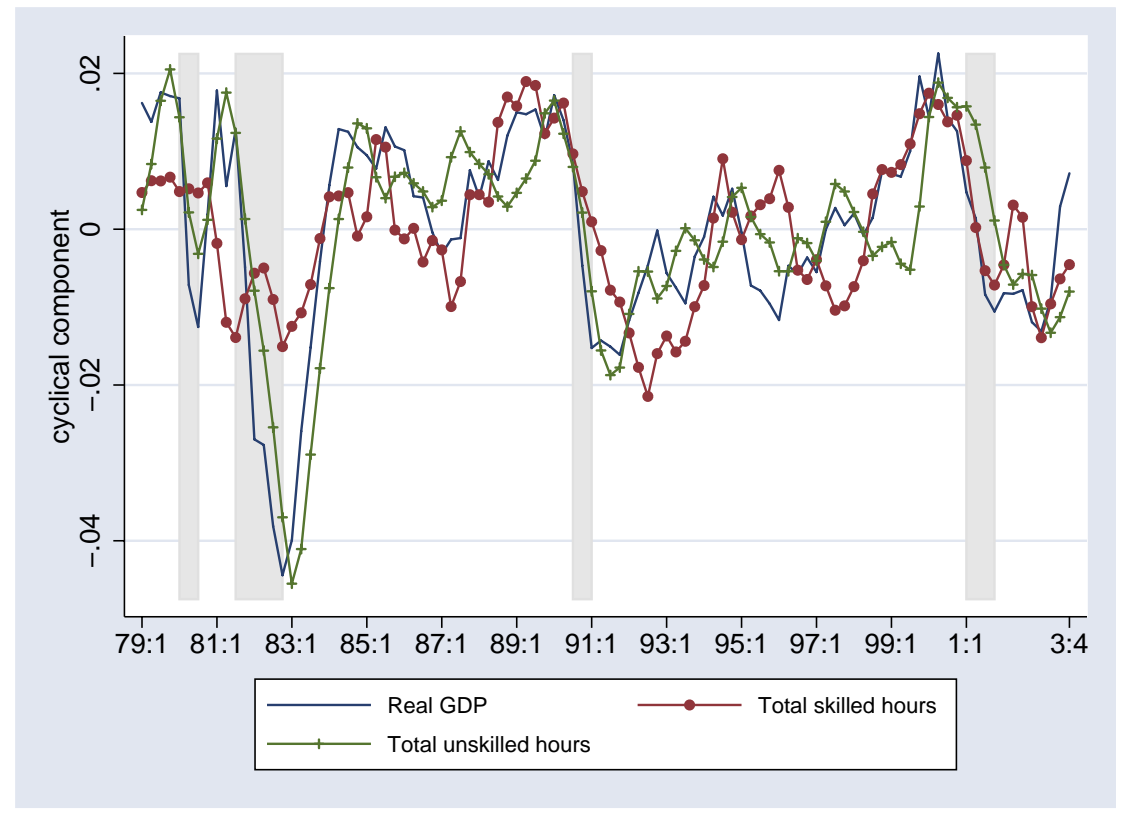

Figure 2: Total Hours per Skill Group: Cyclical Components

Finally, each series is detrended using the Hodrick-Prescott (HP) filter with parameter 1600, as is standard with quarterly data.

Figure 2 shows the cyclical behavior of total hours per skill group, together with real GDP. A quick glance at this figure reveals a clear difference between the first and the second halves of our sample. In the first two NBER recessions (1980 and 1981-82), the unskilled labor input is strongly procyclical and essentially as volatile as output. ${ }^{11}$ The skilled labor input, instead, is not very volatile. The last two recessions (1990-91 and 2001) display a remarkably different pattern: the skilled input becomes strongly procyclical and essentially as volatile as both GDP and the unskilled input.

This dramatic increase in the absolute volatility of skilled labor is remarkable because, as documented by McConnell and Perez-Quiros (2000), Stock and Watson (2002) and many others, the volatility of most macroeconomic aggregates has declined since the mid-1980's.

In Figure 3 we present the rolling standard deviations of GDP, unskilled and skilled hours. In each quarter $t$ the figure represents the standard deviations of the cyclical component of these variables computed using observations from $t$ to $t+40$. As the figure shows, around the mid-1980's the standard deviations of all variables settle down to a new level, which is significantly lower than

\footnotetext{
${ }^{11} \mathrm{NBER}$ recessions are represented by the shaded areas in the figure.
} 


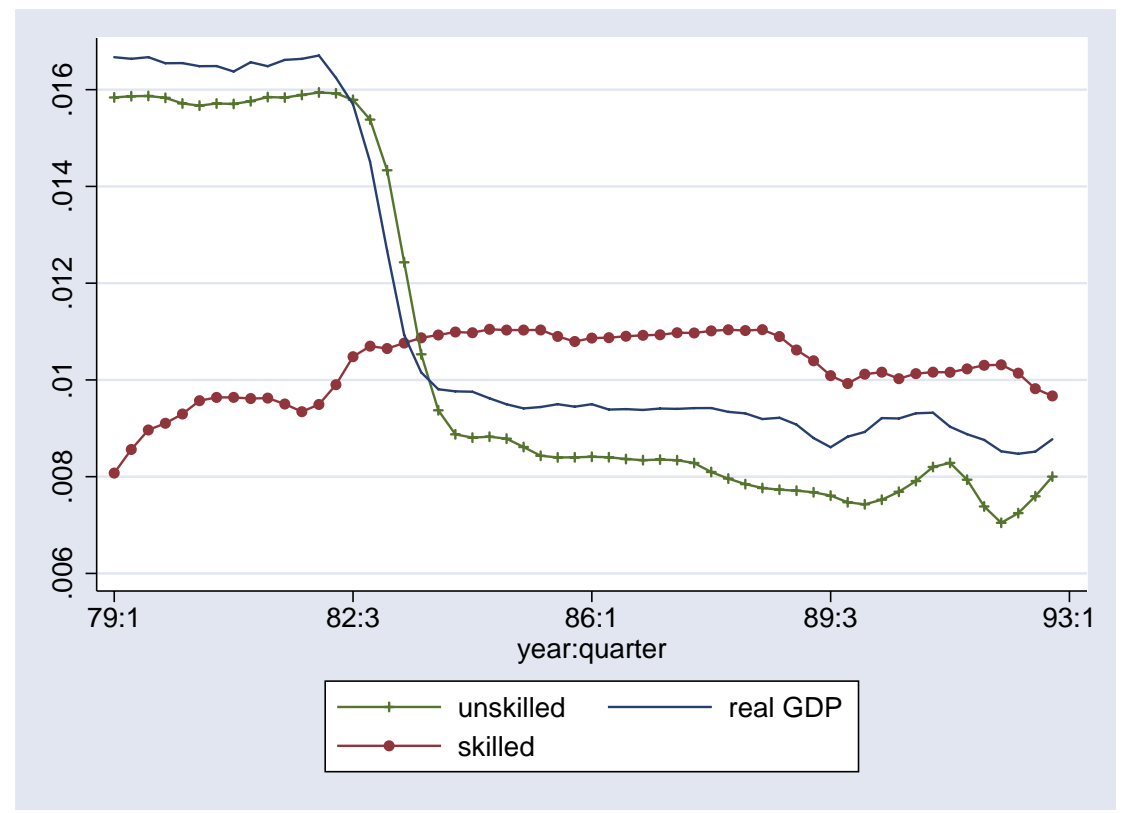

Figure 3: Rolling Standard Deviations (40 quarters ahead) of GDP, Unskilled and Skilled Hours

in 1979 for GDP and unskilled hours, and is actually slightly higher for skilled hours. In our view this is the main puzzle that has to be addressed: why didn't skilled hours become less volatile when business cycle volatility declined?

Using formal tests McConnell and Perez-Quiros (2000) date the break in the volatility of the growth rate of GDP to 1984:1. Based upon this evidence, we split the sample in two sub-periods around 1984:1. For each of the two sub-samples 1979:1-1983:4 and 1984:1-2003:4, we characterize the cyclical behavior of skilled and unskilled labor. ${ }^{12}$

Table 1 summarizes the cyclical properties of total hours of work by skill group and in the aggregate, before and after 1984:1. ${ }^{13}$ In this table we also decompose the fluctuations in total hours into variations in employment (extensive margin) and in working hours per employed workers (intensive margin). In the "Relative Volatility" columns we report the standard deviation of the cyclical component of a variable relative to that of real GDP. The "Comovement" columns, instead, report the contemporaneous correlation between the cyclical component of a variable and the cyclical component of real output.

\footnotetext{
${ }^{12}$ The statistics we present in the following subsections are robust to variations in the break date. We obtained very similar results with alternative break dates, at 1986:4-1987:1 (mid-point of the expansion that started at the trough (1982:4) of the 1981-82 recession and ended at the onset of the 1990-91 recession (1990:3)) and at 1989:4-1990:1 (just before the 1990-1991 recession).

${ }^{13}$ Aggregate hours are obtained by aggregating the hours worked by all individuals in the sample, following the
} 


\begin{tabular}{ll|ccc|ccc} 
& \multicolumn{4}{c}{ Relative volatility } & \multicolumn{3}{c}{ Comovement } \\
\cline { 2 - 7 } & Variable & skilled & unskilled & aggregate & skilled & unskilled & aggregate \\
\hline 1979:1-1983:4 & Total hours & 0.37 & 0.97 & 0.73 & $0.61^{a}$ & $0.88^{a}$ & $0.91^{a}$ \\
& Employment & 0.32 & 0.82 & 0.67 & 0.25 & $0.86^{a}$ & $0.87^{a}$ \\
& Average weekly hours of work & 0.18 & 0.17 & 0.11 & $0.78^{a}$ & $0.90^{a}$ & $0.71^{a}$ \\
\hline 1984:1-2003:4 & Total hours & 1.04 & 0.90 & 0.81 & $0.71^{a}$ & $0.69^{a}$ & $0.80^{a}$ \\
& Employment & 0.93 & 0.81 & 0.73 & $0.66^{a}$ & $0.69^{a}$ & $0.76^{a}$ \\
& Average weekly hours of work & 0.30 & 0.26 & 0.22 & $0.45^{a}$ & $0.28^{b}$ & $0.47^{a}$ \\
\hline
\end{tabular}

Notes: $a, b, c$ denote correlations significant at 1,5 , and 10 percent level respectively.

Table 1: Volatility and co-movement of total hours, employment and average weekly hours per skill group (Household Survey)

From this table we observe that, even though the statistical properties of aggregate hours tend to be similar across the two sub-samples, there is a significant amount of heterogeneity across skill groups. We draw two main conclusions:

Stylized Fact \#1. Before 1984 total hours worked by skilled individuals are procyclical but not very volatile relative to GDP. After 1984 their relative volatility nearly triples. This result is driven by an increase in the relative volatility of skilled employment after $1984 .{ }^{14}$

Stylized Fact \#2. The cyclical properties of total hours worked by unskilled individuals remain roughly constant relative to GDP after 1984. Specifically, their relative volatility remains virtually unchanged and close to one. ${ }^{15}$

Despite the changes in the cyclical behavior of quantities, we do not observe a significant change in the behavior of prices. Table 2 summarizes the cyclical behavior of wages and the skill premium by skill group and in the aggregate, before and after 1984 .

This table shows that, even though the relative price of skilled labor became more volatile after 1984, its correlation with GDP is basically zero in both samples. Our main conclusion is thus that:

Stylized Fact \#3. The skill premium is acyclical both before and after 1984.

efficiency units approach described in Section 2.1.

${ }^{14}$ Interestingly, using Canadian household survey data (Labour Force Survey) on skilled and unskilled employment for the period 1976:1-2002:4 we have found a similar pattern. Specifically, there has been a dramatic increase in the volatility and comovement of aggregate employment for college educated workers in Canada after 1984. Details on these data and on the cyclical properties of labor in Canada are contained in Appendix B.

${ }^{15}$ Unskilled total hours display a one quarter lag with respect to GDP in both subperiods. Notice that the contemporaneous correlation of GDP with unskilled hours, employment, and especially average weekly hours drops after 1984. 


\begin{tabular}{|c|c|c|c|c|c|c|c|}
\hline & \multicolumn{4}{|c|}{ Relative volatility } & \multicolumn{3}{|c|}{ Comovement } \\
\hline & Variable & skilled & unskilled & aggregate & skilled & unskilled & aggregate \\
\hline 1979:1-1983:4 & Hourly wage & 0.75 & 0.57 & 0.63 & 0.29 & $0.41^{c}$ & $0.41^{c}$ \\
\hline & Skill premium & & & 0.26 & & & -0.11 \\
\hline 1984:1-2003:4 & $\begin{array}{l}\text { Hourly wage } \\
\text { Skill premium }\end{array}$ & 0.96 & 0.66 & $\begin{array}{l}0.74 \\
0.60\end{array}$ & $0.35^{a}$ & $0.27^{b}$ & $\begin{array}{c}0.29^{a} \\
0.15\end{array}$ \\
\hline
\end{tabular}

Notes: $a, b, c$ denote correlations significant at 1,5 , and 10 percent level respectively.

Table 2: Volatility and co-movement of the skill premium and wages per skill group and in the aggregate (Household Survey)

\section{Ruling Out Explanations Based on Composition Effects}

As mentioned in Section 2.1, we follow an efficiency units approach to aggregate individual hours data for skilled and unskilled workers. This procedure allows one to control for cyclical variations in the quality of the labor force. However, it is not sufficient to rule out other types of composition effects due to the fact that the structure of the economy is changing over time. For example, one concern is that the sectoral and occupational composition of business cycle fluctuations has changed over time. Another concern is the significant increase in female labor force participation. Due to these effects, it is in principle possible that the observed increase in the relative volatility of aggregate hours worked by individuals with a college degree (Stylized Fact \#1 above) is an artifact of aggregation. In what follows we analyze the MORG data at lower levels of aggregation and show that our results are not due to this type of composition effects.

\subsection{Sectoral Composition}

Do the statistics reported in Section 2.2 reflect the different distribution of skilled and unskilled employment across sectors? It could be argued, for example, that the 1980 and 1981-82 recessions mainly affected the manufacturing sector, where most of unskilled employment tends to be concentrated, while the subsequent recessions affected relatively more the service sector, where most of skilled employment tends to be concentrated.

To address this concern, Table 3 displays the sectoral distribution of total hours worked by skill group and the business cycle statistics of total hours by one digit sector and skill group. ${ }^{16}$ In

\footnotetext{
${ }^{16}$ For the analysis by sectors and occupation, one major difficulty is that our data does not provide a consistent occupational classification over time. Until 1982, it is based on the 1970 Census, but from 1983 until 2002 it is based on the 1980 Census. To overcome this problem, we have developed an assignment between 2-digit occupational codes (and when necessary 3-digit codes) and 1-digit codes. Using this assignment we do not observe any break in the number of people in each 1-digit occupational category from 1982 to 1983 . Notice that our analysis by sectors and
} 
the "Relative Volatility" columns, we report in parenthesis the ratio of post to pre-1984 relative standard deviations. ${ }^{17}$

As the Table suggests, in many service industries (see for example the row "Various Service Industries," which includes Business and Repair Services, Personal Services, Entertainment and Recreational Services, and Professional and Related Services) the volatility of aggregate hours has increased for both skilled and unskilled workers, even if proportionally more for skilled workers. Moreover, within the manufacturing sector the relative volatility of skilled hours has also increased significantly while the relative volatility of unskilled hours has remained approximately constant (as in durables) or increased proportionally less (as in nondurables). ${ }^{18}$ This indicates that our results are not due to differences in the sectoral composition of employment across skilled and unskilled individuals.

More formally, in order to control for these differences, we recomputed the aggregate statistics of Table 1 by imposing that the share of aggregate skilled hours worked in each industry is equal to the analogous share for unskilled hours. To do so, we exploited the fact that the cyclical component of aggregate skilled and unskilled hours, denoted by $\widehat{s}_{t}$ and $\widehat{u}_{t}$, can be expressed (approximately) as the weighted average of the cyclical components $\widehat{s}_{t}^{j}$ and $\widehat{u}_{t}^{j}$ of industries' hours, where the weights $\kappa_{s t}^{j}$ and $\kappa_{u t}^{j}$ are equal to the share of total hours worked in industry $j$ in period $t:^{19}$

$$
\begin{aligned}
& \widehat{s}_{t} \approx \sum_{j=1}^{10} \kappa_{s t}^{j} \widehat{s}_{t}^{j}, \\
& \widehat{u}_{t} \approx \sum_{j=1}^{10} \kappa_{u t}^{j} \widehat{u}_{t}^{j} .
\end{aligned}
$$

occupations is restricted to 1979:1-2002:4 because, from 2003 onwards, the CPS uses yet a different classification system, based upon the 2000 Census.

${ }^{17}$ The statistics on employment and working hours per employed workers are available from the authors upon request. As already observed in the previous section for the broad aggregates, most of the change across the two subperiods is accounted for by changes in the behavior of employment.

${ }^{18}$ In interpreting these disaggregated results, and those of the following subsections, it is worth to keep in mind two issues. First, one should naturally expect the labor aggregates in a given sector (or occupation, as in the next subsection) to display larger volatility than in the aggregate, simply as a result of sectoral idiosyncratic variations that tend to cancel out in the aggregate. The second issue is that the more disaggregated labor inputs have to be computed with a relatively small number of observations. Consequently, some of these disaggregated series are relatively noisy. For the same reason, since the number of observations differs across sectors, comparing the cyclical behavior of labor aggregates across sectors becomes potentially problematic. Thus, in order to try to minimize the effects of this small-sample problem, we prefer to focus on the changes across periods in the relative volatilities of the various labor market aggregates in a given sector.

${ }^{19}$ As a way of checking the validity of this approximation, we have recomputed the moments of Table 1 using the right-hand side of equations (1) and (2) as our measure of the cyclical component of skilled and unskilled hours, obtaining basically the same results as in that table. 


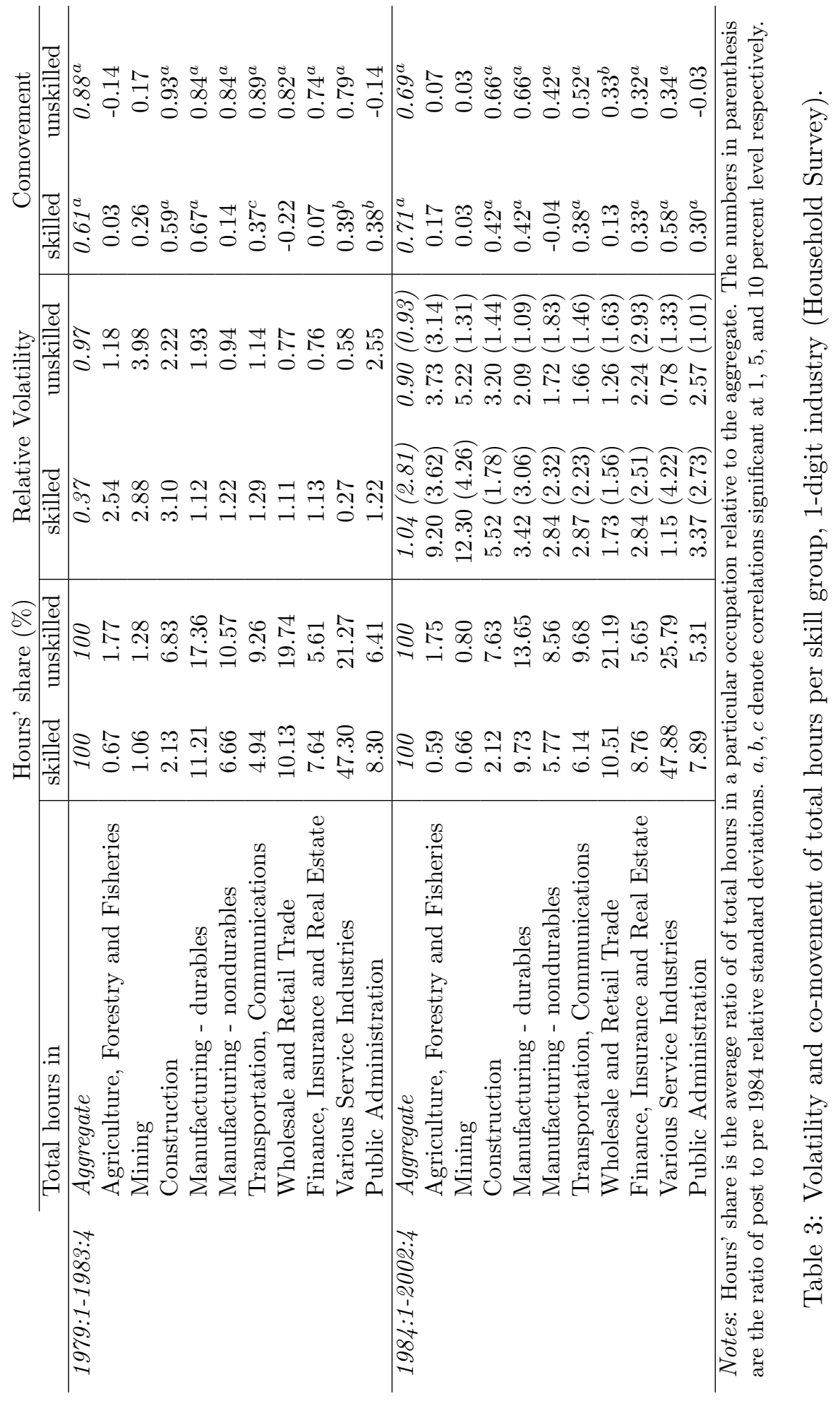


Our experiment consists of constructing a new measure of skilled hours, denoted by $\widehat{s}_{t}^{u}$, which is characterized by the same sectoral distribution as unskilled hours:

$$
\widehat{s}_{t}^{u} \equiv \sum_{j=1}^{10} \kappa_{u t}^{j} \widehat{s}_{t}^{j} .
$$

\begin{tabular}{ll|cc|cc} 
& \multicolumn{2}{c}{ Relative volatility } & \multicolumn{2}{c}{ Comovement } \\
\cline { 3 - 6 } & Variable & skilled $\left(\widehat{s}_{t}\right)$ & skilled $\left(\widehat{s}_{t}^{u}\right)$ & skilled $\left(\widehat{s}_{t}\right)$ & skilled $\left(\widehat{s}_{t}^{u}\right)$ \\
\hline 1979:1-1983:4 & Total Hours & 0.37 & 0.49 & $0.61^{a}$ & $0.67^{a}$ \\
& & & & & $0.71^{a}$ \\
\hline 1984:1-2002:4 & Total Hours & 1.04 & 1.18 & $0.70^{a}$ \\
\hline
\end{tabular}

Notes: $a, b, c$ denote correlations significant at 1,5 , and 10 percent level respectively.

Table 4: Volatility and co-movement of total skilled hours adjusting for sectoral composition effects (Household Survey)

Table 4 reports the cyclical properties of $\widehat{s}_{t}^{u}$. This table reveals that imposing the same distribution of skilled and unskilled hours across sectors tends to make the former more volatile in both sub-periods. The relative volatilities of $\widehat{s}_{t}^{u}$ and $\widehat{s}_{t}$ in the second sub-period exceed the ones in the first sub-period by a factor of, respectively, 2.41 and $2.81 .^{20}$ We conclude that, even after controlling for differences in the composition of hours across sectors, there has been a significant increase in the relative volatility of skilled hours since 1984 .

\subsection{Occupational Composition}

Similar to the previous point, we now evaluate whether Stylized Fact \#1 is due to the fact that skilled workers are particularly concentrated in occupations that have become more cyclical since 1984. Table 5 displays the volatility and comovement with aggregate GDP of total hours by skill group and one-digit occupation.

After 1984 skilled total hours tend to be significantly more volatile and procyclical in the three major occupations for skilled workers. Instead, the cyclical properties of unskilled total hours in these same occupations do not change in an important way after 1984. This observation, therefore,

\footnotetext{
${ }^{20} \mathrm{~A}$ related question is whether the increased volatility of skilled hours is due to an increase in their variances at the sectoral level, or in their covariances. Decomposing the increase in the variance of total skilled hours relative to GDP into these two components reveals that approximately 70 percent of this increase is due to higher sectoral variances and the remaining 30 percent to higher sectoral covariances.
} 


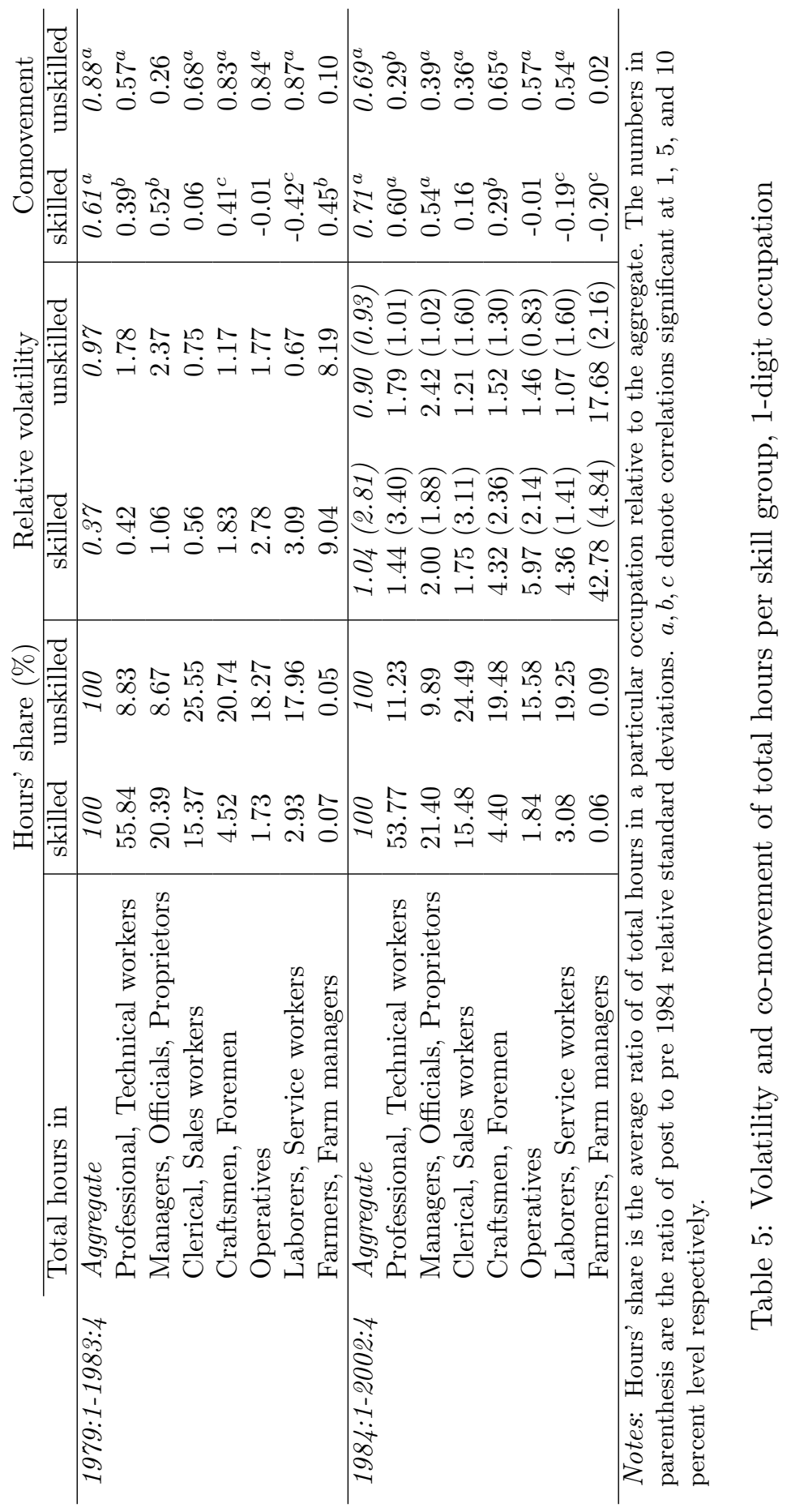




\begin{tabular}{ll|cc|cc} 
& \multicolumn{2}{c}{ Relative volatility } & \multicolumn{2}{c}{ Comovement } \\
\cline { 2 - 6 } & Variable & skilled & unskilled & skilled & unskilled \\
\hline 1979:1-1983:4 & Total hours & 0.45 & 1.00 & $0.38^{c}$ & $0.89^{a}$ \\
& Employment & 0.49 & 0.81 & 0.01 & $0.87^{a}$ \\
& Average weekly hours of work & 0.23 & 0.20 & $0.62^{a}$ & $0.83^{a}$ \\
\hline 1984:1-2003:4 & Total hours & 1.56 & 0.89 & $0.56^{a}$ & $0.61^{a}$ \\
& Employment & 1.34 & 0.77 & $0.48^{a}$ & $0.51^{a}$ \\
& Average weekly hours of work & 0.37 & 0.37 & $0.47^{a}$ & $0.50^{a}$ \\
\hline
\end{tabular}

Notes: $a, b, c$ denote correlations significant at 1,5 , and 10 percent level respectively.

Table 6: Volatility and co-movement of total hours, employment and average weekly hours per skill group - Restricted sample: white, males, aged 31-55

does not lend support to the idea that the change in the dynamics of the skilled labor input after 1984 can be attributed to the increased cyclicality of certain occupations where skilled workers tend to be more concentrated. Table 5 also does not support the idea that skilled total hours have become more cyclical and volatile because skilled workers have been more and more employed in traditionally unskilled occupations. The share of skilled employment in each of the four major occupations for unskilled workers (lines 3 to 6 in Table 5) has been remarkably stable during the sample period.

\subsection{Males vs. Females}

Can the increased volatility of aggregate skilled hours be explained by an increase in the labor force participation of women in the last 25 years? Our concern is that women's hours might be more cyclical than men's due to their higher elasticity of labor supply. To control for potential compositional effects, we restrict attention to the sub-sample of white males workers aged 31 to 55. For this restricted sample, we repeat the analysis of Table 1 and report the results in Table $6 .^{21}$ The results of this exercise not only confirm our stylized facts \#1 and \#2, but also contribute to show that the phenomenon we are documenting affects a category of workers (skilled white males with some work experience) that has been traditionally thought of as relatively insulated from business cycle fluctuations. ${ }^{22}$

\footnotetext{
${ }^{21}$ The associated results for wages and the skill premium are available from the authors upon request.

${ }^{22}$ Focusing on female, rather than male, workers yields qualitatively similar results. The relative standard deviation of total hours increases for both skilled and unskilled females, but proportionally more so for the former group. The relative standard deviation of total hours for skilled females goes from 0.61 to 0.99 , while for unskilled females it goes from 0.76 to 0.92 . The correlation between total hours worked by skilled females and GDP goes from 0.23 before 1984 to 0.52 afterwards, while the analogous correlation for unskilled females declines from 0.72 to 0.59.
} 


\begin{tabular}{ll|ccc|ccc} 
& \multicolumn{4}{c}{ Relative volatility } & \multicolumn{3}{c}{ Comovement } \\
\cline { 2 - 7 } & Variable & skilled & unskilled & aggregate & skilled & unskilled & aggregate \\
\hline 1979:1-1983:4 & Total hours & 0.51 & 0.80 & 0.73 & 0.25 & $0.90^{a}$ & $0.91^{a}$ \\
& Employment & 0.45 & 0.71 & 0.67 & 0.01 & $0.88^{a}$ & $0.87^{a}$ \\
& Average weekly hours of work & 0.19 & 0.13 & 0.11 & $0.62^{a}$ & $0.82^{a}$ & $0.71^{a}$ \\
\hline 1984:1-2003:4 & Total hours & 1.99 & 0.80 & 0.81 & $0.53^{a}$ & $0.75^{a}$ & $0.80^{a}$ \\
& Employment & 1.85 & 0.74 & 0.73 & $0.50^{a}$ & $0.71^{a}$ & $0.76^{a}$ \\
& Average weekly hours of work & 0.33 & 0.21 & 0.22 & $0.27^{b}$ & $0.44^{a}$ & $0.47^{a}$ \\
\hline
\end{tabular}

Table 7: Volatility and co-movement of total hours, employment and average weekly hours per skill group: alternative skill definition (skilled workers must have a master degree). Legend: $a, b, c$ denote correlations significant at 1,5 , and 10 percent level, respectively.

\subsection{Skills vs. Education}

The share of the labor force accounted for by workers with a college degree has increased steadily over the sample period, from 18 percent in 1979 to 29 percent in 2003 . This trend might have been accompanied by a change in the distribution of workers' unobserved skills for at least two reasons: a reduction in the quality of college education over time and/or a change in the pattern of selection into college education. For both reasons, workers who obtained a college degree in more recent years could have less unobserved skills than college educated workers from older cohorts. This composition effect might explain the higher volatility of aggregate hours worked by college educated individuals after 1984 .

In order to partially address this concern, we change our definition of skilled labor. Skilled workers are now those with at least a master's degree (or with at least 18 years of school attendance), and unskilled workers are all the remaining. Underlying this approach is the idea that the composition effects mentioned above would mostly affect the unobserved quality of individuals who have obtained a college degree after 1984, and relatively less the quality of individuals obtaining a master degree. For this alternative definition of skill, we repeat the analysis of Table 1 in Table 7.23

The results clearly indicate that the standard deviation of aggregate skilled hours has risen dramatically after 1984, even adopting this more restrictive definition of skills. ${ }^{24}$ As further evidence

\footnotetext{
${ }^{23}$ The associated results for wages and the skill premium are available from the authors upon request.

${ }^{24}$ Notice that, with this new definition of skilled workers, the relative volatility of skilled labor tends to be higher than in Table 1. This is likely due to the fact that the measure of aggregate skilled labor obtained using the "Master" cutoff has to be computed with less observations than the benchmark measure in Table 1. As pointed out before, we think that in this case it is more meaningful to look at the ratio of post-to-pre 1984 relative volatilities, rather than at their absolute levels.
} 
that there has not been a reduction in the "skill content" of a college degree relative to a high school one, Card and DiNardo (2002) document that the rise in the skill premium since the early 1980's has been concentrated among younger workers aged 26-35. Thus, it seems unlikely that changes in the distribution of unobserved skills can explain our Stylized Fact \#1.

In conclusion, the analysis of this section shows that the increased volatility of aggregate skilled hours is likely not an artifact of aggregation, but rather a robust stylized fact. In the rest of the paper we propose and empirically evaluate some explanations for this fact.

\section{Capital-Skill Complementarity and the Business Cycle}

In addition to documenting the stylized facts reported in the previous section, the goal of this paper is to try to advance a candidate explanation for them. Since the cyclical properties of unskilled

hours, relative to GDP, have not changed significantly during the sample period (Stylized Fact \#2), our goal, in what follows is to try to explain Stylized Fact \#1:

- In the pre-1984 period, skilled hours are significantly less volatile than unskilled hours and GDP.

- In the post-1984 period, skilled hours become roughly as volatile as unskilled hours and GDP.

We begin with a description of our framework, which is further discussed in Section 4.2. Section 4.3 illustrates qualitatively our hypothesis, while Section 5 develops its quantitative implications.

\subsection{Framework}

We follow Krusell, Ohanian, Ríos-Rull, and Violante (2000) and derive the relative demand for skilled and unskilled workers from this production function:

$$
y_{t}=z_{t} k_{s t}^{\alpha}\left[\mu u_{t}^{\sigma}+(1-\mu)\left(\lambda k_{e t}^{\rho}+(1-\lambda) s_{t}^{\rho}\right)^{\sigma / \rho}\right]^{(1-\alpha) / \sigma}
$$

where $y_{t}$ denotes output, $z_{t}$ total factor productivity, $u_{t}$ and $s_{t}$ total unskilled and skilled hours, respectively. $k_{s t}$ and $k_{e t}$ are, respectively, the stock of capital structures and capital equipment. The distinction between the two types of capital will be important for our quantitative analysis: 
they have been growing at significantly different rates, and equipment is likely to exhibit the highest degree of complementarity with skilled labor.

In this production function, the direct elasticity of substitution between unskilled labor and either skilled labor or capital equals $1 /(1-\sigma)$, and the direct elasticity of substitution between skilled labor and capital equals $1 /(1-\rho)$.

Assuming perfectly competitive factor markets, profit maximization yields the inverse relative demand for skilled workers:

$$
\omega_{t}=\frac{(1-\mu)(1-\lambda)}{\mu}\left(\frac{s_{t}}{u_{t}}\right)^{\sigma-1}\left[\lambda\left(\frac{k_{e t}}{s_{t}}\right)^{\rho}+1-\lambda\right]^{\frac{\sigma-\rho}{\rho}},
$$

where $\omega_{t}$ denotes the skill premium:

$$
\omega_{t}=\frac{w_{t}^{s}}{w_{t}^{u}}
$$

and $w_{t}^{j}$ is the real hourly wage of a worker of type $j=s, u$. It is important to notice that equation (4) holds even in the absence of perfect competition in the output market, ${ }^{25}$ and it is consistent with different sources of business cycle fluctuations, either productivity or monetary shocks. In this sense, our insights apply both to Real Business Cycle and to New Keynesian models.

Equation (4) has been used by Krusell, Ohanian, Ríos-Rull, and Violante (2000) to study the long-run behavior of the skill premium. Their exercise consists of using data on the input ratios $s_{t} / u_{t}$ and $k_{e t} / s_{t}$, together with estimates of the production function's parameters, to predict the low frequency variations in the skill premium over the period 1963-1992.

Our main focus is, instead, on the cyclical dynamics of the skill premium and the input ratios. In order to introduce a relative supply for skilled labor at the cyclical frequency, we decompose each variable $x_{t}$ in equation (4) into a trend component, $x_{t}^{T}$, and cyclical component $x_{t}^{c}$. The latter is defined as

$$
x_{t}^{c}=\frac{x_{t}}{x_{t}^{T}}
$$

\footnotetext{
${ }^{25}$ In general, the labor demand for each type of worker equals

$$
w_{t}^{j}=\left(1+m_{t}^{-1}\right) M P_{j t}, j=s, u
$$
}

where $m_{t}$ denotes the price elasticity of output demand faced by the firm, and $M P_{j t}$ is the (physical) marginal product of factor $j$. If the output market is competitive, $m_{t}=\infty$. 
Using this notation, equation (4) can be rewritten as:

$$
\omega_{t}^{c}=\frac{(1-\mu)(1-\lambda)}{\mu \omega_{t}^{T}}\left(\frac{s_{t}^{c} s_{t}^{T}}{u_{t}^{c} u_{t}^{T}}\right)^{\sigma-1}\left[\lambda\left(\frac{k_{e t}^{c} k_{e t}^{T}}{s_{t}^{c} s_{t}^{T}}\right)^{\rho}+1-\lambda\right]^{\frac{\sigma-\rho}{\rho}} .
$$

The relationship between the cyclical component of the skill premium, $\omega_{t}^{c}$, and the ratios of the cyclical components of skilled and unskilled total hours $s_{t}^{c} / u_{t}^{c}$ is represented in Figure 4 . In drawing this curve we take as given the trends $\omega_{t}^{T}, s_{t}^{T} / u_{t}^{T}, k_{e t}^{T} / s_{t}^{T}$, as well as the ratio of the cyclical components of capital and skilled labor $k_{e t}^{c} / s_{t}^{c}$. This relative demand curve is downward sloping in the space $\left(s_{t}^{c} / u_{t}^{c}, \omega_{t}^{c}\right)$ because a firm is willing to hire more skilled hours only at a lower relative wage (relative quantity effect). Moreover, if $\sigma>\rho$, the production function (3) displays capital-skill complementarity and an increase in $k_{e t}^{c} / s_{t}^{c}$ gives rise to an outward shift of this curve (capital-skill complementarity effect). ${ }^{26,27}$

We add to Figure 4 a perfectly elastic relative supply of skilled hours at the business cycle frequency:

$$
\omega_{t}^{c}=v
$$

This yields a skill premium that does not display any cyclical variations, which is consistent with the empirical evidence discussed in Section 2.1. From a theoretical point of view, a perfectly elastic relative supply at the business cycle frequency would emerge in an indivisible labor model with skilled and unskilled workers, along the lines of Rogerson (1988) and Hansen (1985). In such model, the skill premium would be proportional to the ratio of the constant disutilities from work experienced by the two types of agents. ${ }^{28}$

The effect of capital-skill complementarity on the relative volatility of skilled labor is represented in Figure 4. In a recession, firms wish to employ less unskilled labor. Therefore, $u_{t}^{c}$ declines. If the relative demand curve did not shift, the fact that the skill premium is constant would imply that $s_{t}^{c}$ would decrease proportionally to $u_{t}^{c}$, in order to keep the ratio $s_{t}^{c} / u_{t}^{c}$ constant. In this case, which

\footnotetext{
${ }^{26}$ Fallon and Layard (1975) show that capital-skill complementarity is in fact characterized by the same condition on the parameters of the production function (3) even if alternative definitions of the elasticity of substitution are used, namely either the elasticity of complementarity or the Hicks-Allen elasticity of substitution. Differently from the notion of direct elasticity of substitution used in the text, these alternatives yield elasticities which depend upon input shares, as well as on production function parameters.

${ }^{27}$ Krusell, Ohanian, Ríos-Rull, and Violante (2000) estimate equation (4), given the observed behavior of the labor inputs and capital stock in the U.S. for the period 1963-92, and find support for the hypothesis that $\sigma>\rho$.

${ }^{28}$ Prasad (1996) considers such model.
} 


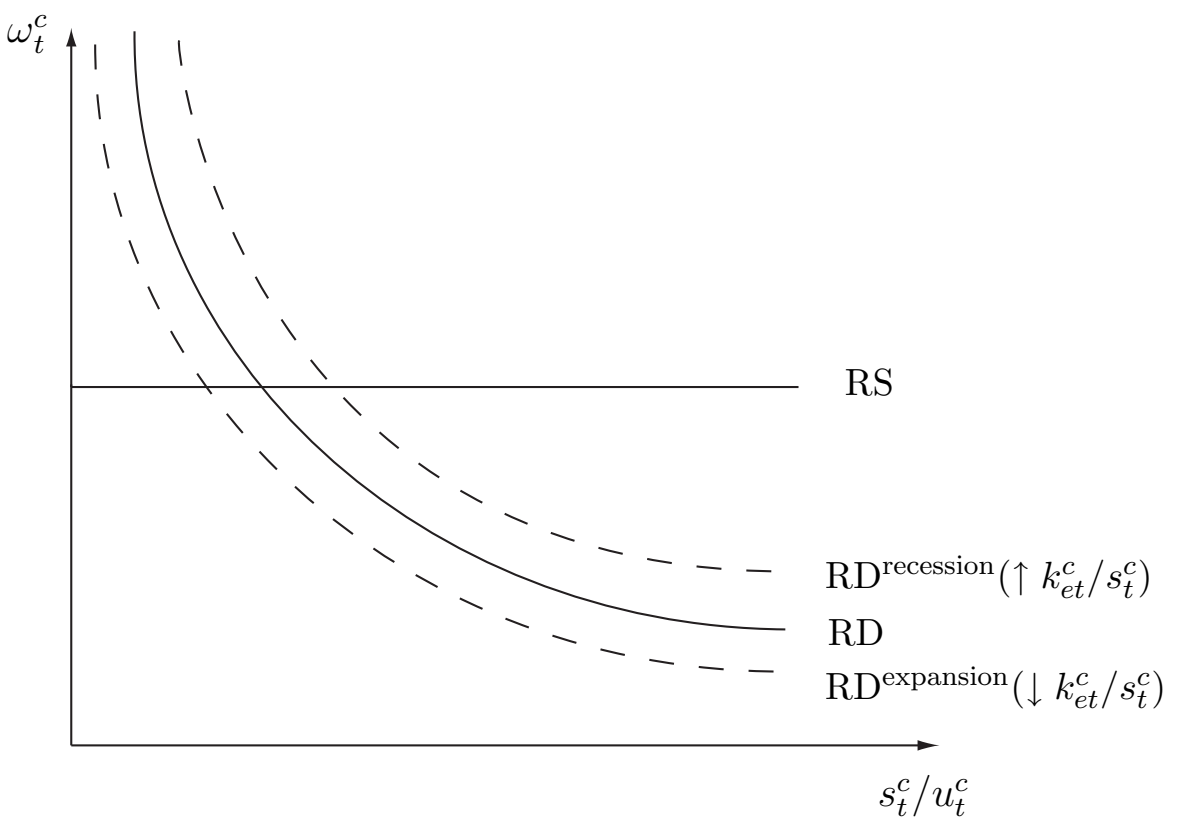

Figure 4: Capital-Skill Complementarity and the Business Cycle

corresponds to a Cobb-Douglas production function, the volatilities of skilled and unskilled hours would be the same. However, the relative demand curve does shift. In particular, if the capital stock does not vary much at the business cycle frequency, variations in $k_{e t}^{c} / s_{t}^{c}$ are dominated by variations in $s_{t}^{c}$. The relative demand curve, therefore, shifts outward in a recession. This is because fewer skilled workers work with a given stock of capital, and hence their productivity increases relative to that of unskilled workers. For given skill premium, the outward shift in relative demand causes the ratio $s_{t}^{c} / u_{t}^{c}$ to move countercyclically, so that the fall in skilled hours is proportionally smaller than the fall in unskilled hours. ${ }^{29}$

\subsection{Discussion}

Before proceeding, it is useful to discuss some aspects of our modelling strategy.

We chose not to use a full-fledged general equilibrium model, but rather focus on the relative supply and demand equations that characterize the equilibrium of the labor market in the shortrun. We use this equilibrium condition to ask the following question: given the long-run dynamics of the skill premium, and the observed behavior of unskilled hours and capital equipment, how much of the short-run behavior of skilled hours is accounted for by the model?

\footnotetext{
${ }^{29}$ The potential for capital-skill complementarity to generate large cyclical movements in production workers/unskilled labor is also stressed by Chang (2000).
} 
This type of approach has been employed in different areas of macroeconomics. For example, within the context of a representative agent model, Prescott (2004) exploits the equality between the marginal product of labor and the marginal rate of substitution between consumption and leisure, to derive an expression for labor supply as a function of aggregate consumption, output and the labor tax rate. He then replaces US and European data in this expression and derives predicted series for per-capita hours worked in these countries. Similarly, in the consumption-based asset pricing literature (see, e.g., Kocherlakota (1996)) it is common to use a parameterized version of the Euler equation, together with the actual series for aggregate consumption, in order to derive predicted series for asset returns.

A second motivation for focusing exclusively on the labor market equilibrium, is that it is not obvious how to make a general equilibrium business cycle model consistent with the "non-balanced growth" kind of dynamics exhibited by the series for capital, the two labor inputs, and the skill premium. For example, along the balanced growth path of a general equilibrium version of our model, the skill premium and the relative quantities of inputs would have to be constant, rather than increasing, as in the data. ${ }^{30}$ We chose not to pursue this approach because, empirically, these trends play an important role, as they allow us to calibrate the parameters of the model (see Section $5)$.

Instead, this partial equilibrium approach allows us to cleanly connect our exercise with the literature on the long-run behavior of the skill premium. ${ }^{31}$ In this literature, researchers commonly derive a relative demand function for skilled workers analogous to the one in equation (4). Then, they take as given the series for the supplies of labor and either derive implications for the dynamics of skill-biased technical change for given behavior of the skill premium (see e.g., Katz and Murphy (1992)), or obtain predictions for the behavior of the skill premium for given behavior of the capital stock (see e.g., Krusell, Ohanian, Ríos-Rull, and Violante (2000)). In addition to specifying the relative demand for skilled labor, which holds at all frequencies, we also specify a perfectly elastic

\footnotetext{
${ }^{30}$ Lindquist (2004) considers a general equilibrium real business cycle model with capital skill complementarity in production. His model is calibrated with reference to the average ratio of unskilled to skilled labor and the average skill premium in the sample period 1979-2002. However, these ratios display significant trends over that period.

${ }^{31}$ In taking this frictionless view of the labor market, we do not intend to minimize the potential roles played by firm-specific human capital, insurance contracts, search and matching, wage rigidities, etc. in accounting for the stylized facts of Section 2. Instead, we view our exercise as a first step, based on the simplest representation of labor market interactions, towards their explanation. In Section 7 we speculate on some of these possible complementary explanations.
} 
short-run relative supply. It is simple to show that this would be the case in a stationary business cycle model characterized by indivisible labor (Hansen (1985)). However, as suggested above, we prefer not to work with a stationary version of the model in order to retain the low-frequency variations of the series for the skill premium and the production inputs. Underlying this approach is the view that the decision of workers of a given educational background to supply more or less hours in response to cyclical variations in real wages is fundamentally different from the decision of whether to acquire more skills in face of secular changes in the skill premium. We think it is appropriate to study the former problem separately from the latter.

\subsection{Hypothesis}

In order to try to explain our pre and post-1984 stylized facts, it is convenient to derive an analytical expression for the volatility of skilled hours. To do so, first equalize relative supply to relative demand at the business cycle frequency to obtain:

$$
\omega_{t}^{T}=\frac{(1-\mu)(1-\lambda)}{\mu v}\left(\frac{s_{t}^{c} s_{t}^{T}}{u_{t}^{c} u_{t}^{T}}\right)^{\sigma-1}\left[\lambda\left(\frac{k_{e t}^{c} k_{e t}^{T}}{s_{t}^{c} s_{t}^{T}}\right)^{\rho}+1-\lambda\right]^{\frac{\sigma-\rho}{\rho}} .
$$

Then, assume for simplicity that there are no low frequency variations in the variables that enter this equation: $\omega_{t}^{T}=\omega, s_{t}^{T}=s, u_{t}^{T}=u, k_{e t}^{T}=k_{e}$. Last, linearize equation (5) to obtain $s_{t}^{c}$ as function of $u_{t}^{c}$ and $k_{e t}^{c}$ :

$$
s_{t}^{c}=\frac{1}{1+Q} u_{t}^{c}+\frac{Q}{1+Q} k_{e t}^{c} .
$$

where the constant $Q$ is defined as:

$$
Q \equiv \frac{\sigma-\rho}{1-\sigma} \frac{\lambda\left(\frac{k_{e}}{s}\right)^{\rho}}{\lambda\left(\frac{k_{e}}{s}\right)^{\rho}+1-\lambda}
$$

Under the assumption that the covariance between $u_{t}^{c}$ and $k_{e t}^{c}$ is zero, it follows from equation (6) that $^{32}$

$$
\frac{\operatorname{var}\left(s_{t}^{c}\right)}{\operatorname{var}\left(u_{t}^{c}\right)}=\left(\frac{1}{1+Q}\right)^{2}+\left(\frac{Q}{1+Q}\right)^{2} \frac{\operatorname{var}\left(k_{e t}^{c}\right)}{\operatorname{var}\left(u_{t}^{c}\right)} .
$$

\footnotetext{
${ }^{32}$ In the data the correlation between $u_{t}^{c}$ and $k_{e t}^{c}$ is equal to 0.36 . Here, we set it equal to zero to simplify our explanation. Of course, in the empirical section of the paper, we allow $u_{t}^{c}$ and $k_{e t}^{c}$ to be positively correlated. See Section 5 for a description of the data for the stock of capital equipment.
} 
This equation contains our main insights concerning the volatility of skilled labor relative to unskilled labor. In what follows, we first describe our hypothesis in a qualitative way. In Section 5, we calibrate the model and evaluate each mechanism quantitatively.

Pre-1984 period. In the data the variance of $s_{t}^{c}$ is lower than the variance of $u_{t}^{c}$. From equation (8), we know that our simple model can qualitatively account for this fact under two conditions: 1) capital-skill complementarity in production $(\sigma>\rho)$, implying $Q>0 ; 2)$ the capital stock is less volatile than unskilled labor: $\operatorname{var}\left(k_{e t}^{c}\right)<\operatorname{var}\left(u_{t}^{c}\right)$. Regarding the latter point, notice that while the stock of physical capital does not display large variations at the business cycle frequency, the flow of services per unit of time provided by this stock might be significantly procyclical, as firms can adjust the workweek of capital along the business cycle. The reason why we did not allow for cyclical capital utilization in our model has to do with the nature of complementarity between skilled workers and capital equipment that we intend to formalize. If skilled workers are needed in order to setup and supervise the work of equipment capital, then variations in the workweek of capital will only have limited influence on the demand for skilled workers, while possibly exerting some influence on their average weekly hours.

Notice that, ceteris paribus, if $\operatorname{var}\left(k_{e t}^{c}\right) / \operatorname{var}\left(u_{t}^{c}\right)$ is low enough, the relative volatility of skilled labor declines with an increase in $Q .{ }^{33}$ In turn $Q$ increases with the degree of capital skill complementarity, measured by $\sigma-\rho$. With a Cobb-Douglas production function, the term $Q$ would be equal to zero and our model would predict that $\operatorname{var}\left(s_{t}^{c}\right)=\operatorname{var}\left(u_{t}^{c}\right)$. The mechanism emphasized here has been first pointed out by Oi (1962) and Rosen (1968) to explain the lower cyclicality of skilled labor, but, to our knowledge, it has not been quantitatively evaluated.

Post-1984 period. In the post-1984 period, the variance of $s_{t}^{c}$ increases significantly relative to the variance of $u_{t}^{c}$. The variances of these two variables are approximately equal after 1984. In what follows we focus on three effects that can potentially explain this change.

1. Reduction in degree of capital-skill complementarity. Our main candidate explanation for the increase in the relative volatility of skilled hours is represented by a reduction in the degree of capital skill complementarity. Mechanically, a reduction in $\sigma-\rho$ leads to a reduction in $Q$, which tends to increase $\operatorname{var}\left(s_{t}^{c}\right) / \operatorname{var}\left(u_{t}^{c}\right)$. The key question is, of course, whether and when such decline

\footnotetext{
${ }^{33}$ Since capital is not very cyclical, the relevant condition is verified in the data.
} 
in the degree of capital-skill complementarity took place. As we discuss in more detail in the next section, this hypothesis is consistent with the long-run behavior of the skill premium $\omega_{t}^{T}$ and the relative inputs $s_{t}^{T} / u_{t}^{T}$ and $k_{e t}^{T} / s_{t}^{T}$ since the late 1980's. During this period, and relative to the early 1980's, the growth rate of the skill premium slows down considerably. This deceleration is accompanied by a higher growth rate of the stock of capital equipment relative to skilled hours, and by a slowdown in the growth rate of $s_{t}^{T} / u_{t}^{T}$. In order to reconcile these facts with the capital skillcomplementarity hypothesis it is necessary to postulate a decline in $\sigma-\rho$ that occurred sometime in the late 1980's.

2. Lower absolute volatility of unskilled labor. The absolute volatility of GDP, at the cyclical frequency, has declined substantially around 1984. This fact has been emphasized by many (see e.g. Stock and Watson (2002)). In Section 2.2 we have shown how $u_{t}^{c}$ closely tracks the behavior of the cyclical component of GDP. Thus, around 1984, the volatility of $u_{t}^{c}$ has declined substantially. As equation (8) suggests, for given $Q$ and $\operatorname{var}\left(k_{e t}^{c}\right)$, a reduction in $\operatorname{var}\left(u_{t}^{c}\right)$ tends to increase the relative volatility of skilled labor. ${ }^{34}$ The intuition for this result is simple: with capital-skill complementarity, cyclical variations in skilled hours are not only related to cyclical variations in unskilled hours, but also to variations in capital. A decline in the absolute volatility of unskilled hours, therefore, tends to reduce the absolute volatility of skilled hours less than proportionally, leading to an increase in its relative volatility.

3. Higher level of capital equipment relative to skilled labor. The last effect we consider has to do with the dramatic increase in the level of $k_{e t}^{T} / s_{t}^{T}$ that occurred during the sample period. To understand the implications of this trend, consider the effect of a higher $k_{e} / s$ level in equation (7). If $\rho<0$ and $\sigma>\rho$, a higher $k_{e} / s$ leads to a decline in the term $Q$ in (7), and thus to a higher relative volatility of skilled labor over the business cycle. The intuition for this result is as follows. With $\sigma>\rho$, a higher capital stock leads to an increase in the demand for skilled labor (capital-skill complementarity effect). The sign of $\rho$ determines whether a higher level of $k_{e} / s$ tends tends to amplify or reduce the marginal effect of higher capital to skilled labor ratio on the demand for skilled labor. If $\rho=0$ (the Cobb-Douglas case), there is no such level effect. In the empirically relevant case in which $\rho<0$, capital and skilled labor are relatively more complements

\footnotetext{
${ }^{34}$ As we will discuss in Section 5, the absolute standard deviation of $k_{e t}^{c}$ did decline after 1984, together with the reduction in the volatility of output. However, this drop has been proportionally smaller than the one in the absolute standard deviation of $u_{t}^{c}$.
} 
in production than in the Cobb-Douglas case. ${ }^{35}$ This relatively high complementarity implies that, when capital is already abundant relative to skilled labor, a further increase in $k_{e t} / s_{t}$ at the business cycle frequency (induced by a drop in $s_{t}$ ) generates a smaller increase in the demand for skilled labor. Consequently, in this case cyclical fluctuations in the demand for skilled labor would become relatively more related to cyclical variations in the demand for unskilled labor.

The quantitative assessment of these mechanisms is obviously of great interest, and we turn to them in the next section.

\section{Quantitative Analysis}

In this section we calibrate the model and undertake a quantitative analysis of the three mechanisms illustrated in Section 4. In Section 5.1 we consider two of these mechanisms: the lower volatility of unskilled hours and the higher capital-skilled labor ratio that characterize the post-1984 period. To do so, the parameters of the equilibrium relationship (5) are calibrated using data for the whole 1979:1-2002:4 period. ${ }^{36}$ For this reason, we label this exercise "Constant Parameters".

In Section 5.2 we evaluate the effect of our main mechanism, a reduction in the degree of capitalskill complementarity. This "Changing Parameters" exercise is motivated by the difficulty faced by the version of the model with constant parameters in reconciling the lower growth rate of the skill premium in the 1990's with the simultaneous acceleration in the growth rate of the capital-skilled hours ratio.

\subsection{The Lower Volatility of Unskilled Hours and the Higher Capital-Skilled Labor Ratio}

The center of our quantitative analysis is the labor market equilibrium condition (5), which we reproduce below for convenience:

$$
\omega_{t}^{T}=\frac{(1-\mu)(1-\lambda)}{\mu v}\left(\frac{s_{t}}{u_{t}}\right)^{\sigma-1}\left[\lambda\left(\frac{k_{e t}}{s_{t}}\right)^{\rho}+1-\lambda\right]^{\frac{\sigma-\rho}{\rho}} .
$$

\footnotetext{
${ }^{35}$ This is consistent with the estimates of Krusell, Ohanian, Ríos-Rull, and Violante (2000) and our own calibration (see Section 5).

${ }^{36}$ Notice that in order to calibrate the model, we use only data up to 2002:4. The reason is that, while the MORG data set extends until 2003:4, the series for capital equipment is not available for 2003.
} 
In Figure 5 we plot the variable $\omega_{t}$, and in Figure 6 the variables $s_{t} / u_{t}$ and $k_{e t} / s_{t} .{ }^{37}$ The series for capital equipment is from Cummins and Violante (2002). ${ }^{38}$ We interpolate their yearly data to obtain quarterly observations, by imposing a constant quarterly rate of growth within each year.

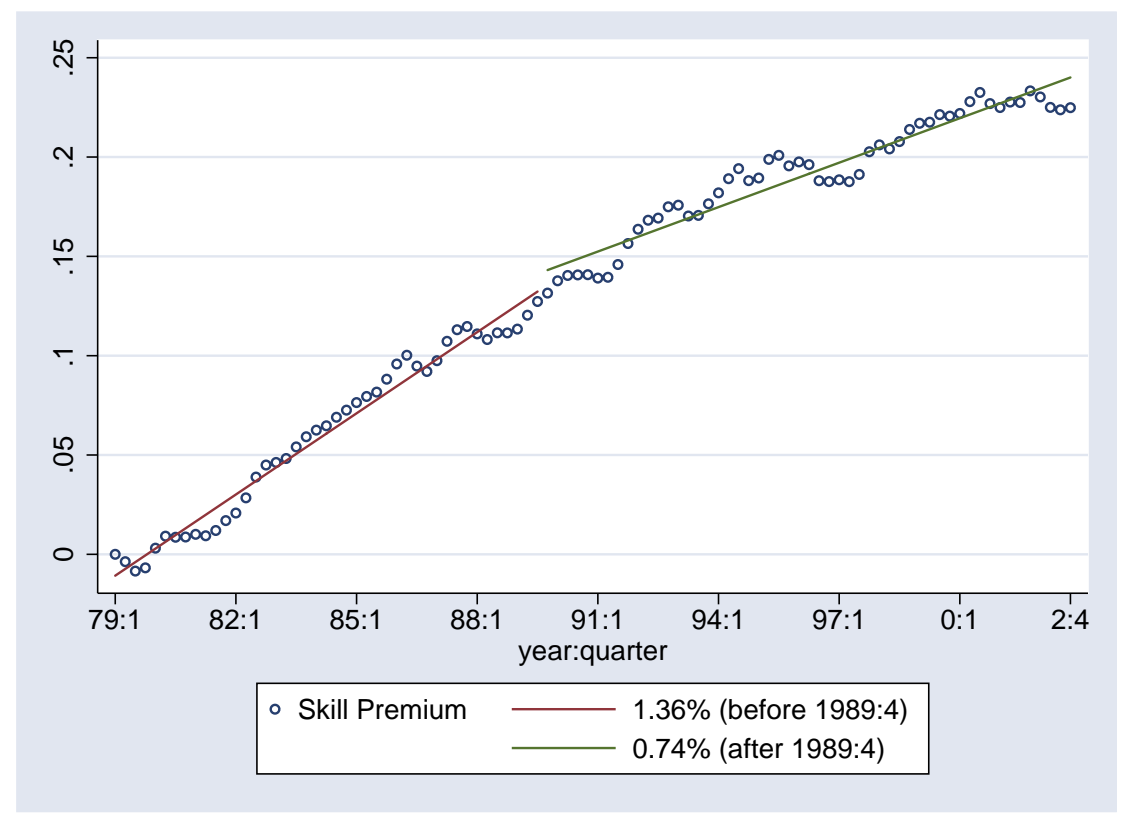

Figure 5: Skill premium

Figures 5 and 6 are to be interpreted jointly in terms of equation (9). Over the entire sample period 1979:1-2002:4, the skill premium and the ratio of skilled to unskilled hours display an upward trend. Given the increase in the ratio of the stock of capital equipment to skilled hours, these two trends can only be reconciled, within our framework, by the existence of capital-skill complementarity in production.

For our quantitative exercise we need to specify values for the parameters $\sigma, \alpha, \rho, \lambda$ and $\mu$ in equation (9). ${ }^{39}$ We set $\sigma=0.4$ and $\alpha=0.13$. The value for $\sigma$ has been estimated by Krusell, Ohanian, Ríos-Rull, and Violante (2000). Their estimate is consistent with the values obtained by other authors (see Autor, Katz, and Krueger (1998) for a review). The parameter $\alpha$ represents the

\footnotetext{
${ }^{37}$ The key feature of these series that we wish to emphasize for the purposes of the exercise in this section is that they all display upward trends. In the next section we will explore the fact that these trends have in fact changed over time.

${ }^{38}$ The capital equipment series is based upon the Cummins and Violante (2002) series of quality-adjusted equipment prices. The latter extrapolates Gordon (1990)'s quality-adjusted series, which span only the 1947-1983 period, until 2000. We extrapolate the Cummins-Violante series to the year 2002. In order to compute the growth rate of the stock of equipment from 2000 to 2003, we compute the growth rate of the series published by the BEA and add to it the average amount by which the growth rate of the Cummins-Violante series exceeds the published data over the period 1979-2000.

${ }^{39}$ Notice that $v$ in equation (9) is just an arbitrary scale parameter, so it does not need to be calibrated.
} 


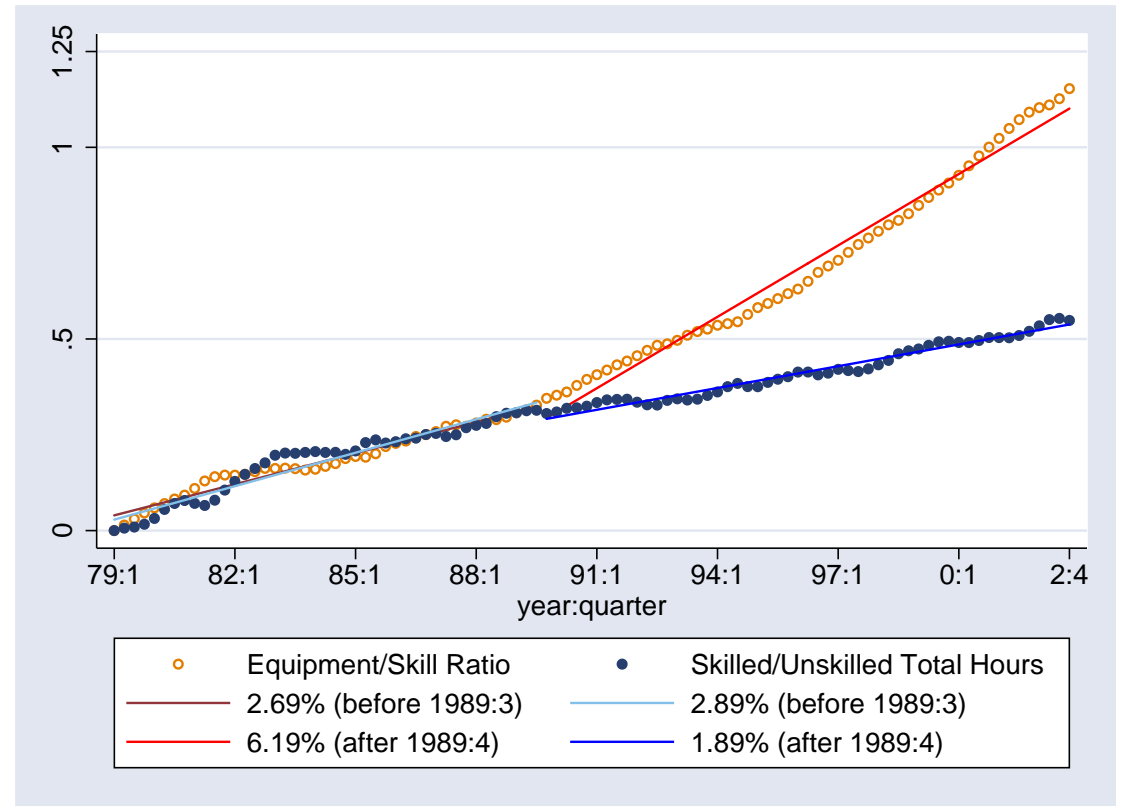

Figure 6: Equipment-Skill and Skilled-Unskilled Input Ratios

\begin{tabular}{ccclc}
\hline Period & Parameters & Values & \multicolumn{1}{c}{ Target Moments } & Values \\
\hline 1979:1-2003:4 & $\lambda$ & 0.73 & Average labor share in GDP & 0.70 \\
& $\mu$ & 0.54 & Average wage bill ratio & 0.56 \\
& $\rho$ & -0.88 & Average yearly growth rate of skill premium & $1.06 \%$ \\
\hline
\end{tabular}

Table 8: Calibration under Constant Parameters

share of capital structures in GDP and has also been taken from Krusell, Ohanian, Ríos-Rull, and Violante (2000). We select $\mu$ and $\lambda$ in order to match the average wage bill ratio and aggregate labor share over the entire period 1979:1-2002:4. ${ }^{40}$ Unlike the case of $\sigma$, estimates of $\rho$ in the literature tend to be more dispersed. We pick the substitution parameter $\rho$ in order to match the average growth rate of the skill premium in the entire sample, computed by regressing the logarithm of the skill premium on a constant and time trend. Regarding the computation of the data moments, the aggregate labor share of income is set at 0.70, consistently with NIPA data. In addition, we use the CPS data to construct the average wage bill ratio and the average growth rate of the skill premium.

Table 8 summarizes our calibration exercise under a constant production structure. It contains

\footnotetext{
${ }^{40}$ One has to worry about whether the skill premium predicted by equation (9) is invariant to the unit in which capital equipment is measured. It turns out that this is indeed the case: it is relatively easy to show that different measurement units are fully absorbed by the share parameters $\lambda$ and $\mu$ in our calibration.
} 


\begin{tabular}{ll|cc|cc} 
& \multicolumn{2}{c}{ Relative volatility } & \multicolumn{2}{c}{ Comovement } \\
\cline { 2 - 6 } & Total Hours & skilled & unskilled & skilled & unskilled \\
\hline 1979:1-1983:4 & Data & 0.37 & 0.97 & 0.61 & 0.88 \\
& Benchmark & 0.61 & & 0.63 & \\
\hline 1984:1-2002:4 & Data & 1.05 & 0.91 & 0.73 & 0.74 \\
& Benchmark & 0.79 & & 0.69 & \\
& Constant $k_{e t} / s_{t}$ after 1984 & 0.76 & & 0.69 & \\
\hline
\end{tabular}

Table 9: Quantitative Results under Constant Parameters

the values of the calibrated parameters together with the data moments that they match.

To evaluate the performance of the model, we use the actual series for $u_{t}, k_{e t}$ and $\omega_{t}^{T}$ (computed as the HP-filter trend of $\omega_{t}$ ) together with the calibrated parameters (Table 8) in equation (9), to obtain a predicted series $\hat{s}_{t}$ for skilled hours. We then HP-filter $\hat{s}_{t}$ to extract its cyclical component $\hat{s}_{t}^{c}$. Figure 7 plots the actual series for $s_{t}$ together with $\hat{s}_{t}$. Figure 8 reports $\hat{s}_{t}^{c}$, together with the the cyclical components of output and actual total skilled hours.

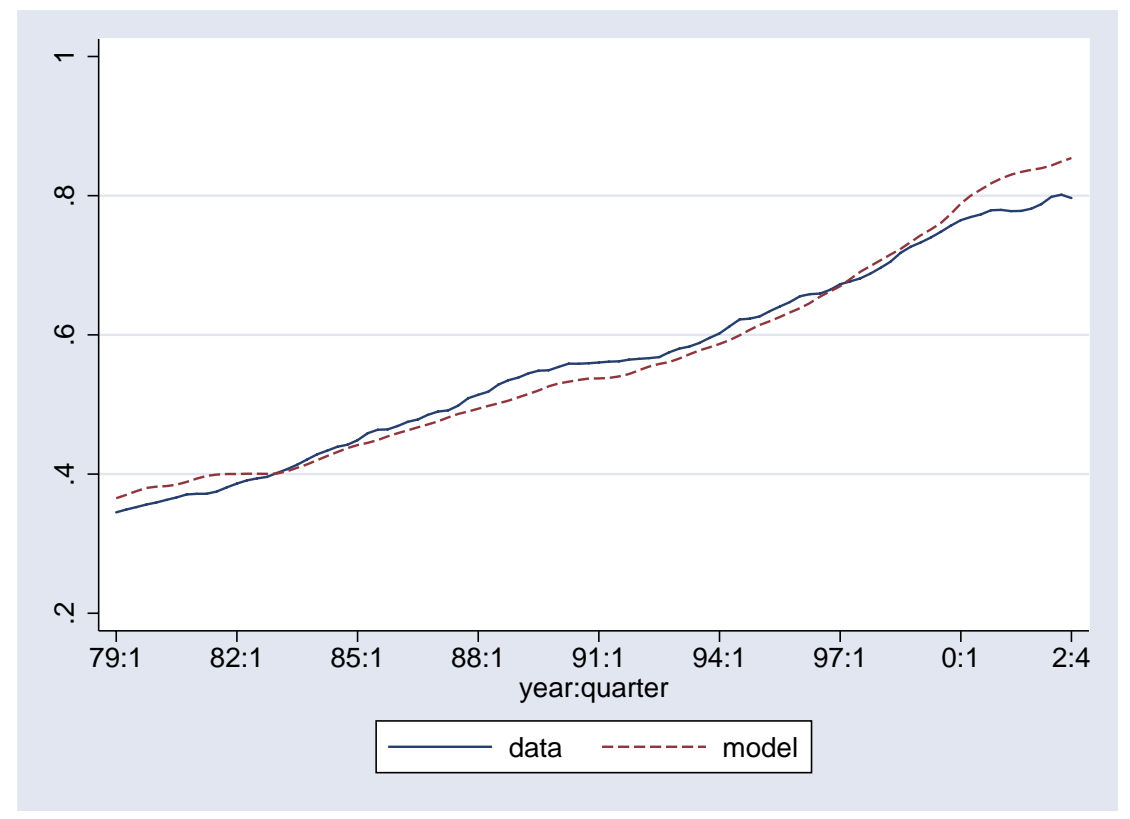

Figure 7: Model Fit for the Total Skilled Hours under Constant Parameters

Table 9 contains the cyclical properties of skilled hours predicted by our model, before and after 1984. This is our "benchmark" exercise under constant parameters, when both effects considered in this section are at work.

In interpreting these results recall that, with no capital-skill complementarity in production 


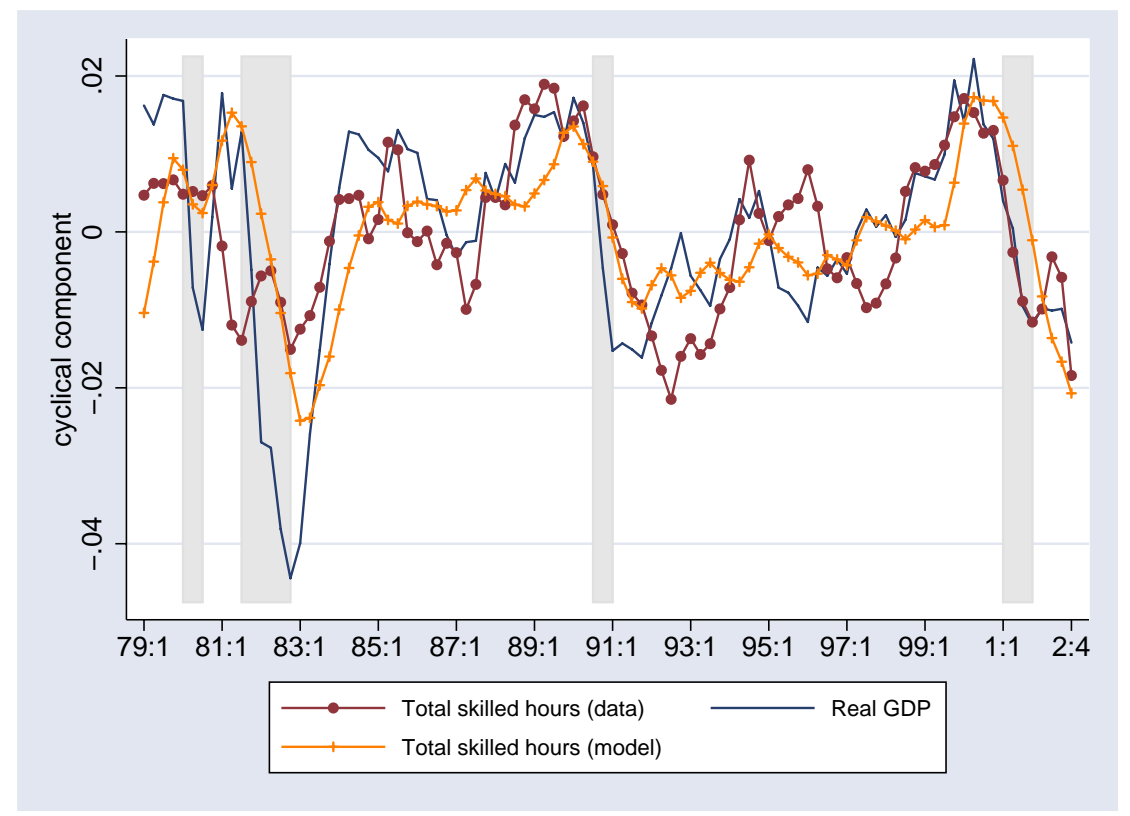

Figure 8: Model Performance under Constant Parameters: Cyclical Components

$(\sigma=\rho)$, the ratio of the standard deviations of skilled and unskilled hours would equal one in both sub-periods. ${ }^{41}$ The existence of capital-skill complementarity in production, by itself, explains why the relative standard deviation of skilled hours is significantly smaller than one before 1984 .

After 1984, the relative standard deviation of skilled hours increases by 17 percentage points (from 0.61 to 0.79 ), which is about a quarter of the increase observed in the data. This change is due to the two effects considered in this section. First, the absolute volatility of the cyclical component of unskilled hours $\left(u_{t}^{c}\right)$ has declined dramatically after 1984, while the volatility of the cyclical component of capital equipment $\left(k_{e t}^{c}\right)$ did not change in a significant way over the sample period. In the data, $s t d\left(k_{e t}^{c}\right) / s t d\left(u_{t}^{c}\right)$ increased from 0.50 before 1984:1 to 0.91 after this date. This fact in conjunction with capital-skill complementarity implies that, as explained in Section 4, the volatility of skilled hours will drop proportionally less than the volatility of unskilled hours and GDP. Second, the ratio $k_{e t} / s_{t}$ has increased over the sample period, especially in the 1990's, when its growth rate more than doubled. If $\rho<0$, as in our benchmark calibration, this increase should have increased the relative volatility of skilled hours.

In order to get a sense of the relative contribution of each of these two effects, we have performed a simple experiment with equation (6). For given coefficient $Q$, and for given actual series for the

\footnotetext{
${ }^{41}$ As a consequence, the volatility of skilled hours relative to GDP would also be approximately equal to one in both subperiods.
} 
cyclical components of unskilled hours and capital equipment, this equation can be used to obtain a predicted series for the cyclical component of skilled hours. We have computed the value of the coefficient $Q$ such that the predicted series for skilled hours displays a relative standard deviation for the period 1979:1-1983:4 equal to the one predicted by the benchmark case (i.e., 0.61). The relative standard deviation of skilled hours after 1983:4 obtained using this procedure is reported in Table 9 under the label "Constant $k_{e t} / s_{t}$ after 1984". This figure, 0.76, represents the relative volatility of skilled hours in the sub-period following 1984, under the assumption that the coefficient $Q$, and therefore the ratio $k_{e t} / s_{t}$, stays constant at its pre-1984 value. ${ }^{42}$ This result suggests that most of the increase in the relative volatility of skilled hours explained by the constant parameter model can be attributed to the lower volatility of unskilled hours over the business cycle.

\subsection{The Decline in Capital-Skill Complementarity}

In this section we evaluate the magnitude of the third mechanism described in Section 4 . We have argued that the increase in the relative volatility of skilled hours might be attributed, at least in part, to a reduction in the degree of capital-skill complementarity in the economy. In what follows we first provide some empirical evidence in favor of this hypothesis and discuss how the latter might be justified from a theoretical point of view. We then evaluate its contribution to the cyclical behavior of skilled hours.

The decline in capital-skill complementarity. Our starting point is the observation that assuming a constant set of parameters for the whole sample period (the benchmark case of the previous section) implies that the model is not able to replicate the long-run behavior of the skill premium, as Figure 9 suggests.

The principal reason for this failure is that the trends in the skill premium and the input ratios appear to change sometime around the late 1980's. Figure 5 shows a decline in the average growth rate of the skill premium between the 1979:1-1989:3 and 1989:4-2002:4 sub-periods (the reason for splitting the sample around 1989:4 for the purpose of looking at the long-run trends will become clear later in this section).

In the first sub-period, the skill premium has grown, on average, at a rate of $1.36 \%$ per year,

\footnotetext{
${ }^{42}$ Notice that a trend in $k_{e} / s$ would induce a trend in the coefficient $Q$.
} 


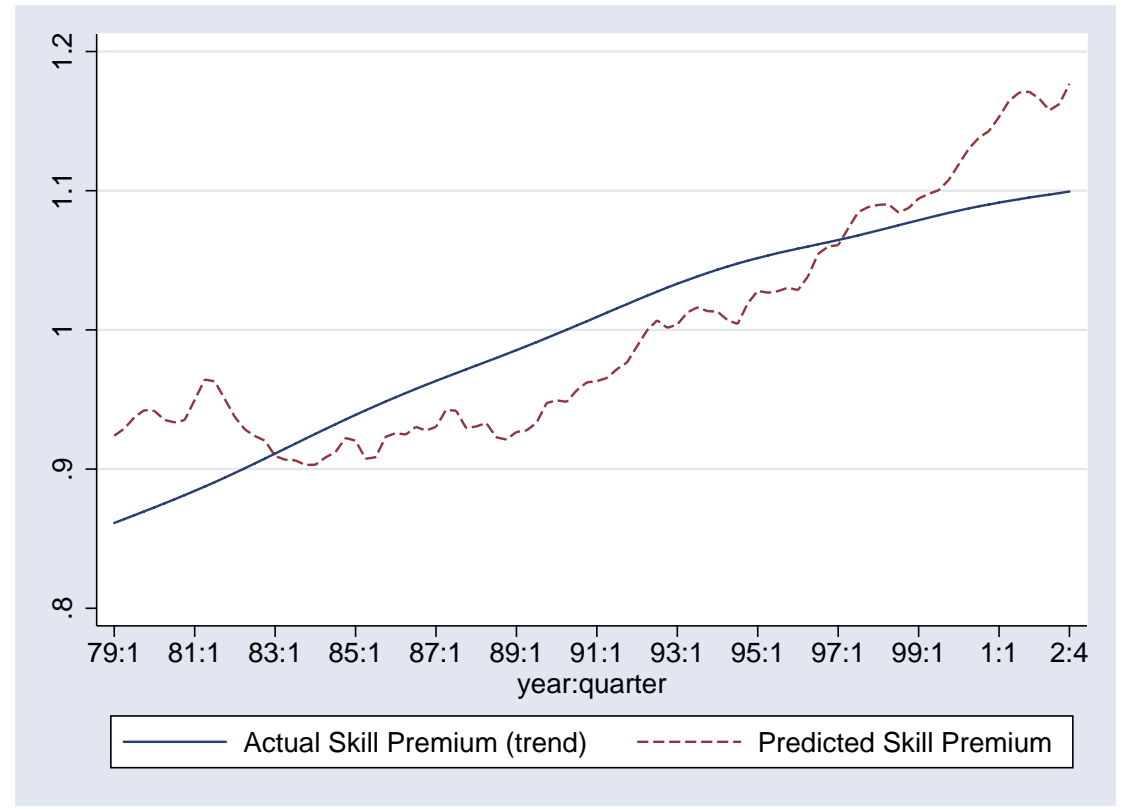

Figure 9: Model Fit for the Skill Premium under Constant Parameters

while in the second period it has grown at an average rate of $0.74 \%$ per year. Figure 6 depicts the evolution of the relative inputs $k_{e t} / s_{t}$ and $s_{t} / u_{t}$. This figure shows a substantial acceleration after 1989:3 in the growth rate of $k_{e t} / s_{t}$ (from $2.69 \%$ to $6.19 \%$ per year) and a contemporaneous slowdown in the growth of $s_{t} / u_{t}$ (from $2.89 \%$ to $1.89 \%$ per year). ${ }^{43}$ These observations accord well with the empirical evidence presented by Card and DiNardo (2002) and Beaudry and Green (2002), who also notice that the skill premium has grown at a significantly smaller rate after about 1987 with respect to the previous seven years, despite an acceleration in the growth rate of the stock of capital equipment.

The evolution of $k_{e t} / s_{t}$ and $s_{t} / u_{t}$ since the late 1980's represents a challenge to the view that the long-run behavior of the skill premium in the 1980's and 1990's can be explained using a production structure characterized by capital-skill complementarity and constant parameters. The latter would have predicted a faster, rather than a slower, increase in the skill premium since 1989, because the faster growth in $k_{e t} / s_{t}$ and the slower growth in $s_{t} / u_{t}$ should have made skilled labor relatively more productive than in the first sub-period (see also Figure 9). Instead, Figure 5 clearly

\footnotetext{
${ }^{43}$ The increase in the growth rate of $k_{e t} / s_{t}$ can be traced back to a substantial decline in the relative price of equipment in terms of consumption, brought about by a significant acceleration in the technological progress specific to the production of capital equipment goods. In part as a consequence of this fact, investment in equipment has accelerated in the post-1989 period, and most notably in the late 1990's. This is consistent with anecdotal evidence suggesting that the 1990's where a boom period in terms of investment in equipment.
} 
tells otherwise. ${ }^{44}$

Our view is that this evidence simply points to a reduction in the degree of complementarity in production between skilled labor and capital equipment starting from the late 1980's. The lower degree of capital-skill complementarity would then contribute to explain the increase in the relative volatility of skilled hours over the business cycle.

To evaluate the importance of this effect for the cyclical behavior of skilled hours, we follow a simple approach, and assume a once-and-for-all decline in $\sigma-\rho$ in the production function (3). In reality, of course, this decline is likely to have been a slowly-evolving process spanning several years, presumably due to the diffusion and routinization of computers and information technologies, and reaching maturity around the late 1980's. Katz (1999) (page 17) has interpreted the slowdown in the growth of the relative demand for skill since the late 1980's, as reflecting a "maturing of the computer revolution", whereby "as technologies diffuse and become more routinized the comparative advantage of the highly skilled declines." This view is in fact consistent with the theoretical model proposed by Greenwood and Yorokoglu (1997) to describe the effects of the faster decline in the price of equipment since 1974 on the relative demand for skilled labor. Along the same line, Blanchard (2003) (page 281) conjectures that "it is likely that computers will become easier and easier to use in the future, even by low skill workers. Computers might even replace highskill workers, those workers whose skills involve primarily the ability to compute or to memorize." We argue that this phenomenon might have already begun since the late 1980's.

Business cycle implications. In order to evaluate the importance of the evidence described above for the cyclical properties of skilled labor, we recalibrate the model allowing for a different degree of capital-skill complementarity after a certain break date in the late 1980's.

In order to set values for the model's parameters and determine a precise break date, we proceed as follows. First, for a given break date $T$, we assume that while the parameters $\rho, \mu$ and $\lambda$ of the production function (3) may take on different values before and after $T$, the parameters $\alpha$ and $\sigma$ remain instead unchanged over the entire sample period. The values of $\rho, \mu$ and $\lambda$ for the

\footnotetext{
${ }^{44}$ Figure 9 and Figure 7 are obviously closely related, as they are two different ways of conveying the same information. In the constant production structure model, the sharp increase in capital equipment that took place during the 1990s induces a significant increase in relative productivity of skilled labor, all else constant. Since the actual $s / u$ ratio does not grow any faster in the 1990s, this must lead to a faster growth in the predicted skill premium (Figure 9). Similarly, since the actual skill premium does not grow any faster in the 1990s, this must lead to a faster growth in predicted skilled employment (Figure 7).
} 


\begin{tabular}{ccclc}
\hline Period & Parameters & Values & \multicolumn{1}{c}{ Target Moments } & Values \\
\hline 1979:1-1989:3 & $\lambda_{1}$ & 0.92 & Average labor share in GDP & 0.70 \\
& $\mu_{1}$ & 0.57 & Average wage bill ratio & 0.45 \\
& $\rho_{1}$ & -2.21 & Average yearly growth rate of skill premium & $1.36 \%$ \\
\hline 1989:4-2002:4 & $\lambda_{2}$ & 0.56 & Average labor share in GDP & 0.70 \\
& $\mu_{2}$ & 0.52 & Average wage bill ratio & 0.65 \\
& $\rho_{2}$ & -0.40 & Average yearly growth rate of skill premium & $0.74 \%$ \\
\hline
\end{tabular}

Table 10: Calibration under Changing Parameters

sub-period preceding $T$ are set exactly as in Section 5.1, in order to match the average labor share, the average wage bill ratio, and the average growth rate of the skill premium between 1979:1 and $T$. The values of $\rho, \mu$ and $\lambda$ for the sub-period following $T$ are set in an analogous way. For given set of parameters, we then select the break date $T$ that minimizes the sum of squared errors between the trend in the actual skill premium, $\omega^{T}$, and the skill premium predicted by the model. This procedure yields $T=1989: 3$ as the break date.

The results of this calibration exercise are summarized in Table 10. Notice, in particular, how the calibrated elasticity of substitution between skilled labor and capital equipment is now much lower before 1984, and much higher after 1984, compared to the benchmark case of Table 8 .

Before proceeding, a few observations are in order. First, the assumption that the decline in $\sigma-\rho$ is due to an increase in $\rho$, rather than a decrease in $\sigma$, is motivated by the idea that, as computers and information technologies become more routinized, it is the degree of complementarity of skilled labor with capital equipment that might decline. This assumption turns out to be quite innocuous as similar results can be obtained by keeping $\rho$ the same across sub-periods and letting $\sigma$ adjust. Second, after the break date, it is necessary to change $\mu$ and $\lambda$ together with $\rho$, in order to avoid jumps in the predicted series for the skill premium and to guarantee that the model is consistent with the evidence on the average labor income shares in both sub-periods. Third, our break date for the model's parameters (1989:3) occurs a few years after the date (1983:4) in which we break the data series to analyze their cyclical properties. While in a literal sense, it would be more consistent to have these two dates closer to each other, it is unreasonable to interpret the reduction in the volatility of GDP or in the degree of capital-skill complementarity as having occurred in a specific quarter or even year. Instead, we think of both of these phenomena as processes occurring over time. Our approach is aimed at capturing this change in a simple way. 


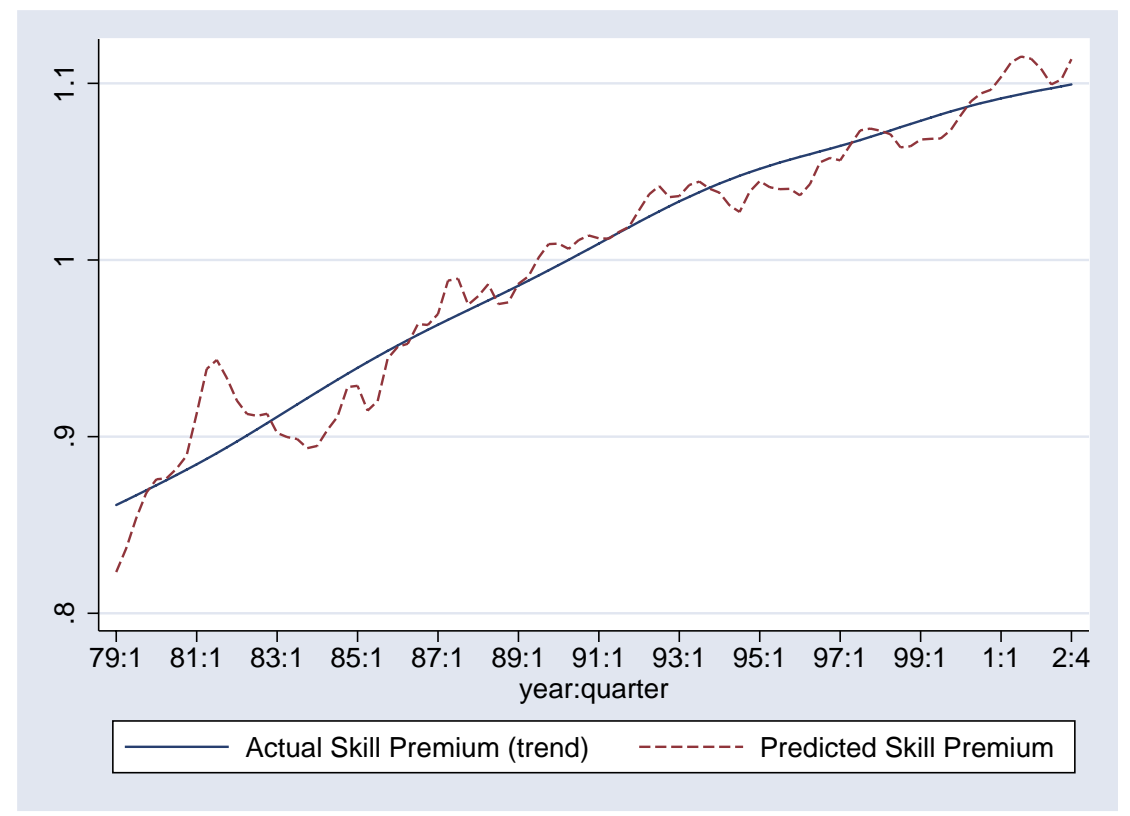

Figure 10: Model Fit for the Skill Premium under Changing Parameters

\begin{tabular}{ll|cc|cc} 
& \multicolumn{2}{c}{ Relative volatility } & \multicolumn{2}{c}{ Comovement } \\
\cline { 2 - 5 } & Total Hours & skilled & unskilled & skilled & unskilled \\
\hline 1979:1-1983:4 & Data & 0.37 & 0.97 & 0.61 & 0.88 \\
& Constant Parameters & 0.61 & & 0.63 & \\
& Changing Parameters & 0.55 & & 0.46 & \\
\hline 1984:1-2002:4 & Data & 1.05 & 0.91 & 0.73 & 0.74 \\
& Constant Parameters & 0.79 & & 0.69 & \\
& Changing Parameters & 0.95 & & 0.67 & \\
\hline
\end{tabular}

Table 11: Quantitative Results: effect of changing capital-skill complementarity

Figure 10 plots the actual data series for the HP-trend in the skill premium, and the skill premium predicted by the model. The key feature illustrated by this figure is the ability of the model to reproduce the slowdown in the growth rate of the skill premium, in spite of the underlying behavior of the relative input ratios.

Figure 11 plots the actual data series for skilled hours $s_{t}$ together with the series $\hat{s}_{t}$. The model appears to provide a good description of the behavior of skilled hours, even at higher frequencies. The overall fit of the model clearly improves compared to Figure 7. We then HP-filter $\hat{s}_{t}$ to extract its cyclical component $\hat{s}_{t}^{c}$. Figure 12 reports $\hat{s}_{t}^{c}$, together with the the cyclical components of output and actual total skilled hours.

Table 11 contains the cyclical properties of skilled hours predicted by our model and compares 


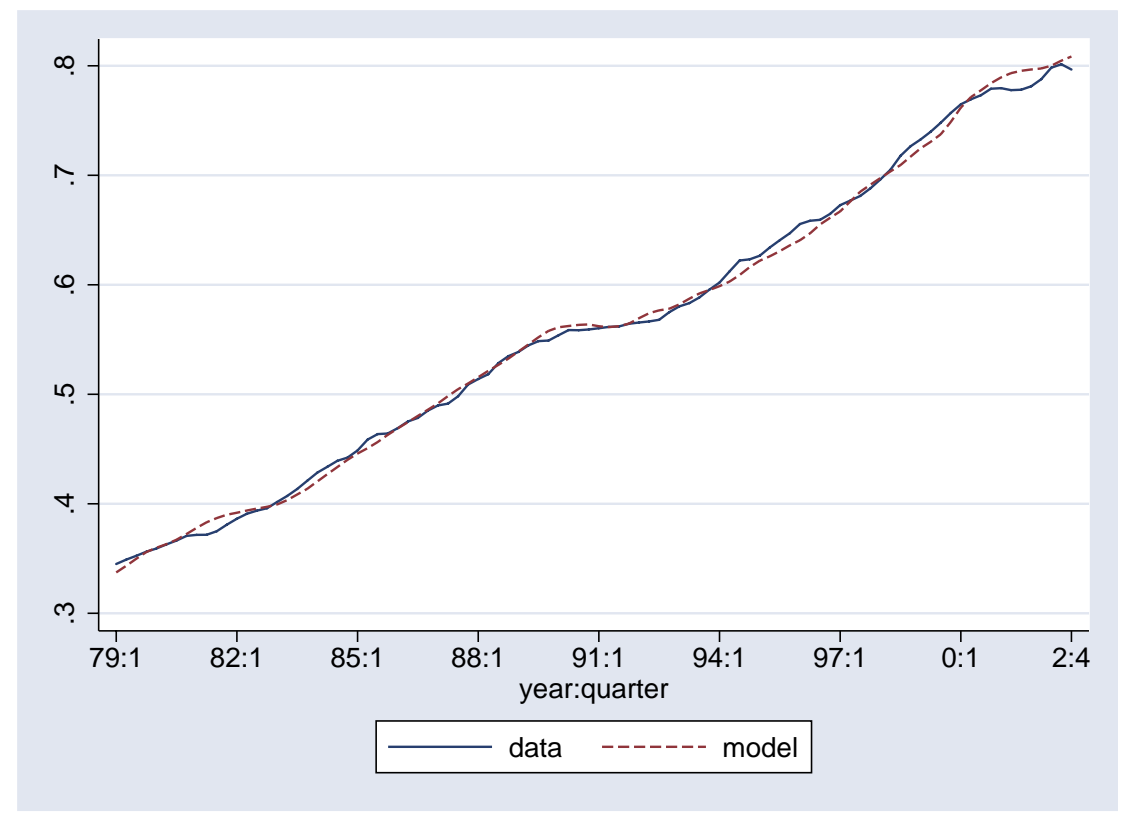

Figure 11: Model Fit for Total Skilled Hours under Changing Parameters

them both with the data and with results of Section 5.1. This table illustrates how the change in the degree of capital-skill complementarity is quantitatively important. In particular, the fact that the degree of capital-skill complementarity before 1984 is higher than in the benchmark calibration, allows this version of the model to predict a lower relative volatility of skilled hours in the first sub-period (0.55 against 0.61). Similarly, the higher degree of capital-skill complementarity in the 1990's generates a larger increase in the relative volatility of skilled hours. The latter is 0.95 in the version of the model with changing parameters against 0.79 in the model with constant parameters. Notice also that the model correctly predicts that skilled hours are more volatile than unskilled hours after 1984 and less volatile before 1984.

In summary, the three effects we have discussed in Section 5.1 can jointly account for almost sixty percent $((0.95-0.55) /(1.05-0.37))$ of the increase in the relative standard deviation of skilled hours observed in the data. Most of the explanatory power of the model comes from the change in the production function parameters (about 55 percent), followed by the decline in the relative standard deviation of unskilled hours (about 37 percent), and the increase in the ratio of capital equipment relative to skilled hours (about 8 percent). ${ }^{45}$

\footnotetext{
${ }^{45}$ We have changed the calibration of the model to evaluate the sensitivity of the results to different values of the elasticity parameter $\sigma$. We have found that, even varying the parameter $\sigma$ beyond the boundaries suggested by the empirical evidence does not improve the performance of the model. Notice that, given our parsimonious
} 


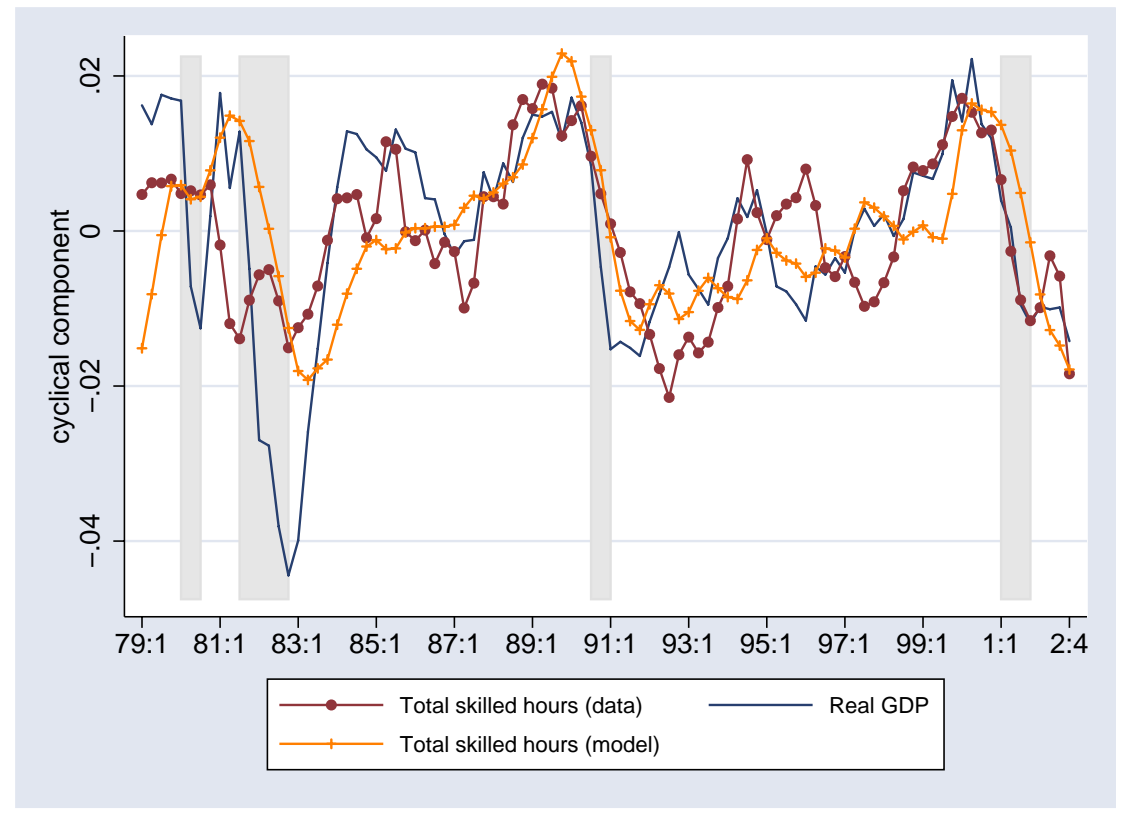

Figure 12: Model Performance under Changing Parameters: Cyclical Components

\section{Before 1979: Evidence From the March CPS}

The quantitative results of Section 5.2 support the hypothesis that the higher volatility of skilled labor observed in the 1990's might be due in part to a decline in the degree of complementarity between skills and capital equipment. As observed above, such a decline is consistent with the view, originally advanced by Nelson and Phelps (1966) and more recently by Greenwood and Yorokoglu (1997), that skilled workers have a comparative advantage in implementing and adopting new technologies. According to this interpretation, the "technological revolution" that started in the mid 1970's, has been characterized by a transition period of 10-15 years. During this transition period the demand for skilled labor accelerated, leading to a fast-growing skill premium and to the acyclicality of skilled labor documented in Section 2.2. After this transition period, starting from the late 1980's, new technologies become more routinized leading to a slowdown in the demand for skilled labor. This slowdown is reflected in the decline in the growth rate of the skill premium and the higher cyclicality of skilled labor.

parameterization, $\sigma$ and the share of structures, $\alpha$, are the only parameters that can, in principle, be set exogenously. Reasonable variations in the latter also do not give rise to noticeably different results from those of Table 11 . While variations in the other, calibrated, parameters of the model, $\lambda, \mu$, and $\rho$, could possibly generate a better fit of the model at the cyclical frequency, they would also oblige us not to be able to capture some of the low frequency variations in the data. Given the role played by the latter in disciplining our empirical exercise we did not pursue this avenue. 


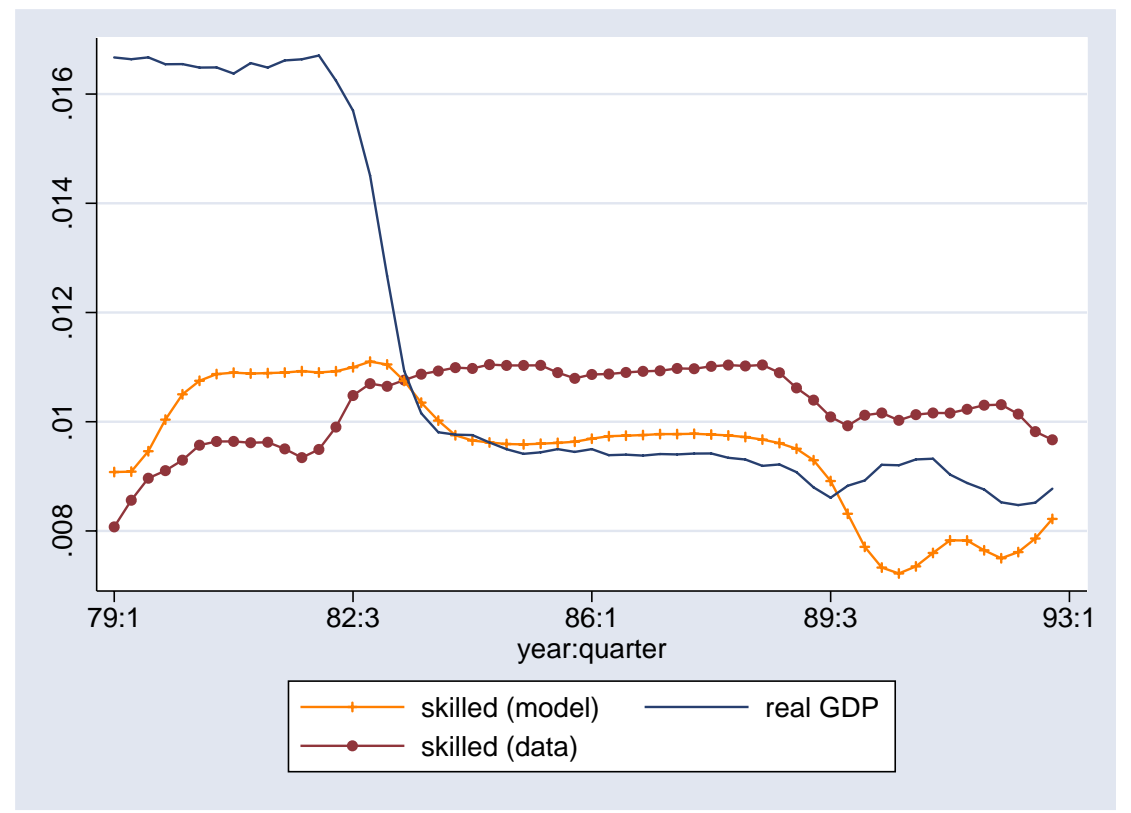

Figure 13: Model Performance under Changing Parameters: Rolling Standard Deviations (40 quarters ahead)

If this line of argument is correct, one should expect skilled labor to be relatively acyclical only during periods of "technological revolutions", such as the late 1970's and early 1980's. In order to evaluate this prediction of our model, we need to provide some evidence regarding the cyclical behavior of skilled labor before 1979. Given that the CPS ORG data are available only since that date, we construct measures of the aggregate skilled and unskilled labor inputs using annual data from the March CPS for the period 1963-2002.

The analysis of Section 2.2 reveals that most of the increase in the volatility of skilled labor since 1984 is due to a higher volatility of aggregate employment, as opposed to average hours. Thus, for simplicity, we focus exclusively on the extensive margin. ${ }^{46}$ Aggregate skilled labor in a given year is measured, using the March CPS survey, as the aggregate number of weeks worked by individuals with a college degree in that year. Aggregate unskilled labor is defined analogously. ${ }^{47}$

Figure 14 represents the HP-filtered series for aggregate skilled and unskilled labor from the March CPS, together with aggregate GDP. ${ }^{48}$ Two features of these data stand out. First, from

\footnotetext{
${ }^{46}$ Before 1976, the March CPS survey only asks individuals how many weeks they have worked last year and how many hours they have worked last week. This presents a limitation in computing a measure of total hours based upon this sample before 1976. Also for this reason we decided to concentrate on aggregate employment.

${ }^{47}$ To make these data as comparable to the ORG ones in Section 2.2 as possible, we use the same sample selection criteria described in the Appendix.

${ }^{48}$ We used a smoothing parameter of 6.25 , as suggested by Ravn and Uhlig (2002) for annual data.
} 


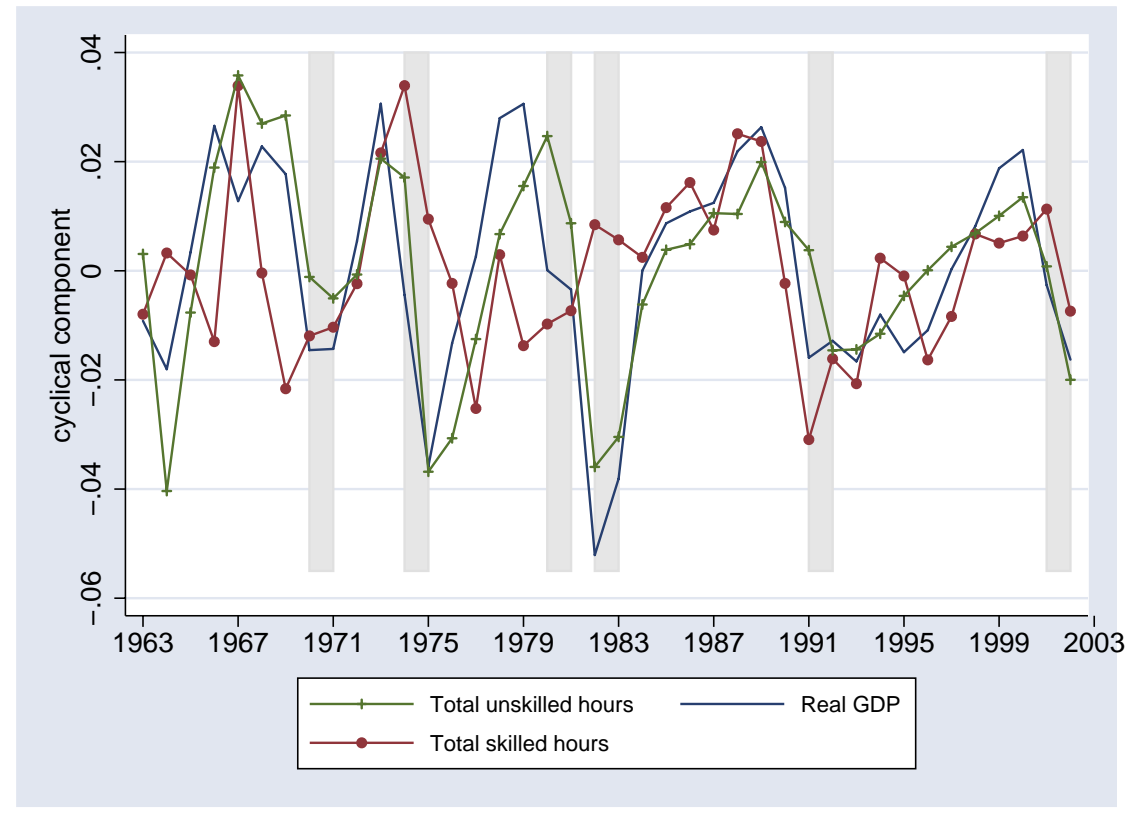

Figure 14: Cyclical Behavior of GDP, Skilled and Unskilled Employment - March CPS

1979 onwards, the cyclical properties of aggregate skilled labor measured using the March CPS data are very similar to the ones obtained using the ORG data, and represented in Figure 2. In particular, aggregate skilled labor is relatively acyclical in the 1980 and 1981-82 recessions, while it is significantly more volatile afterwards. Second, and more important, the March CPS data reveal that in the period between 1963 and 1975, skilled labor tends to be roughly as cyclical as unskilled labor. ${ }^{49}$ In other words, the acyclicality of skilled labor is a transitional phenomenon stretching from the mid-1970's to the mid-1980's. This point can be easily seen by considering, in Figure 15, the rolling standard deviation for skilled and unskilled labor and GDP in the 1963-2002 period. The figure clearly suggests that in the earlier as well as in the later parts of this long sample, the volatility of skilled labor was about the same as the volatility of unskilled labor and GDP. The rolling standard deviation of skilled labor reaches a minimum in the mid-1970's, indicating that the decade 1976-1985 was indeed characterized by the smallest degree of volatility for this variable. ${ }^{50}$

\footnotetext{
${ }^{49}$ This fact requires further comment, as few of the authors cited in the Introduction (particularly Kydland (1984) and Keane and Prasad (1993)) had found skilled labor to be relatively acyclical in earlier studies. We attribute this apparent discrepancy to the fact that these authors use microdata samples for the period 1970-1980 (Kydland) and 1966-1981 (Keane and Prasad) that include information from both the "high volatility" subperiod 1963-1975 and from the "low volatility" subperiod 1976-1983. Additionally, in order to compute measures of the cyclicality of skilled labor, these authors adopt a regression approach in which the unemployment rate in one year is correlated with workers' employment status in the same year. This method fails to account for any leads and lags in the response of skilled labor to cyclical fluctuations in GDP in the 1963-1975 subperiod (see Figure 14).

${ }^{50}$ The relative standard deviation of the HP-filtered measure of skilled labor for the subperiods 1963-1975, 1976-
} 


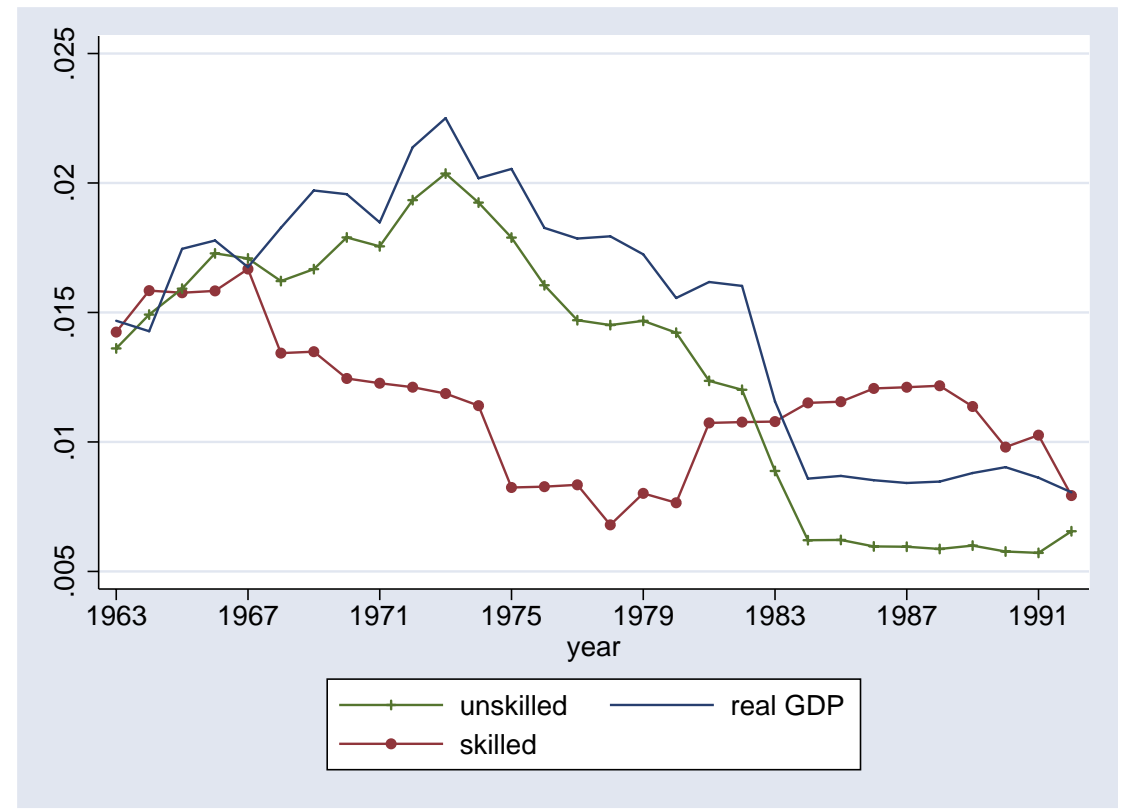

Figure 15: Rolling Standard Deviations (10 years ahead) of GDP, Skilled and Unskilled Employment - March CPS

This observation supports our interpretation of the observed reduction in the volatility of aggregate skilled hours from the mid-1980's.

\section{Alternative Explanations}

In this paper we have focused on the hypothesis that the increase in the volatility of skilled labor since the mid-1980's reflects the end of a decade-long transition period during which the demand for skilled labor accelerated dramatically. In this section, we discuss some alternative explanations.

Our main conclusion is that, unlike ours, none of these explanations provides a comprehensive account of the observed dynamics of input quantities and prices since the early 1960's, both at high and low frequencies. However, while overall successful, our model can only account for about 60 percent of the increase in the relative volatility of skilled labor observed in the data. Thus, some of these explanations might be complementary to ours in accounting for this increase.

1983, 1984-2002 is, respectively, 0.91, 0.45, 1.13. The relative standard deviation of unskilled labor in these three periods is, respectively, $0.98,0.89,0.69$. 


\subsection{Adjustment Costs to Skilled Labor and Temporary vs. Permanent Shocks to GDP}

In the simple model of Section 4 we have for simplicity abstracted from adjustment costs to employment. However, starting from Oi (1962), economists have argued that adjustment costs to skilled labor play an important role in explaining the high frequency dynamics of skilled employment. Thus, faced with temporary cyclical reductions in productivity or product demand, employers would prefer to hoard skilled labor in order not to dissipate costly training costs. Lower adjustment costs for unskilled workers, instead, would make unskilled employment more sensitive to the business cycle.

Within this context, the increase in the volatility of skilled employment documented in Section 2.2 might reflect a change in the nature of business cycle fluctuations. According to this hypothesis, the shocks underlying the recessions in the early part of our sample were temporary, whereas the last two recessions were driven by more permanent shocks.

If a recession is perceived to be temporary, and if skilled workers have higher adjustment costs, firms might respond to a cyclical downturn with temporary layoffs of unskilled workers, but leave their skilled workers in place. If a recession is instead perceived to be more permanent, as this hypothesis would hold was the case since the mid-1980's, then firms would have less incentive to hoard skilled labor. This argument could potentially explain why skilled employment has become relatively more volatile in recent years.

The key question is, of course, whether business cycles shocks have become more permanent in recent years. While this is difficult to measure empirically, there is at least some indirect evidence consistent with this view. Figure 16 plots Bureau of Labor Statistics series representing the aggregate number of unemployed workers and the number of unemployed workers due to temporary layoffs. It is clear from the figure that temporary layoffs tend to increase systematically during all NBER-defined recessions preceding the 1990-91 one. In the last two recessions, instead, temporary layoffs did not increase substantially. ${ }^{51}$ One may interpret this evidence as suggesting that business cycle shocks have become more permanent in recent years, thus leading to less hoarding of skilled workers.

\footnotetext{
${ }^{51}$ Bleakley, Ferris, and Fuhrer (1999) present and discuss similar evidence.
} 


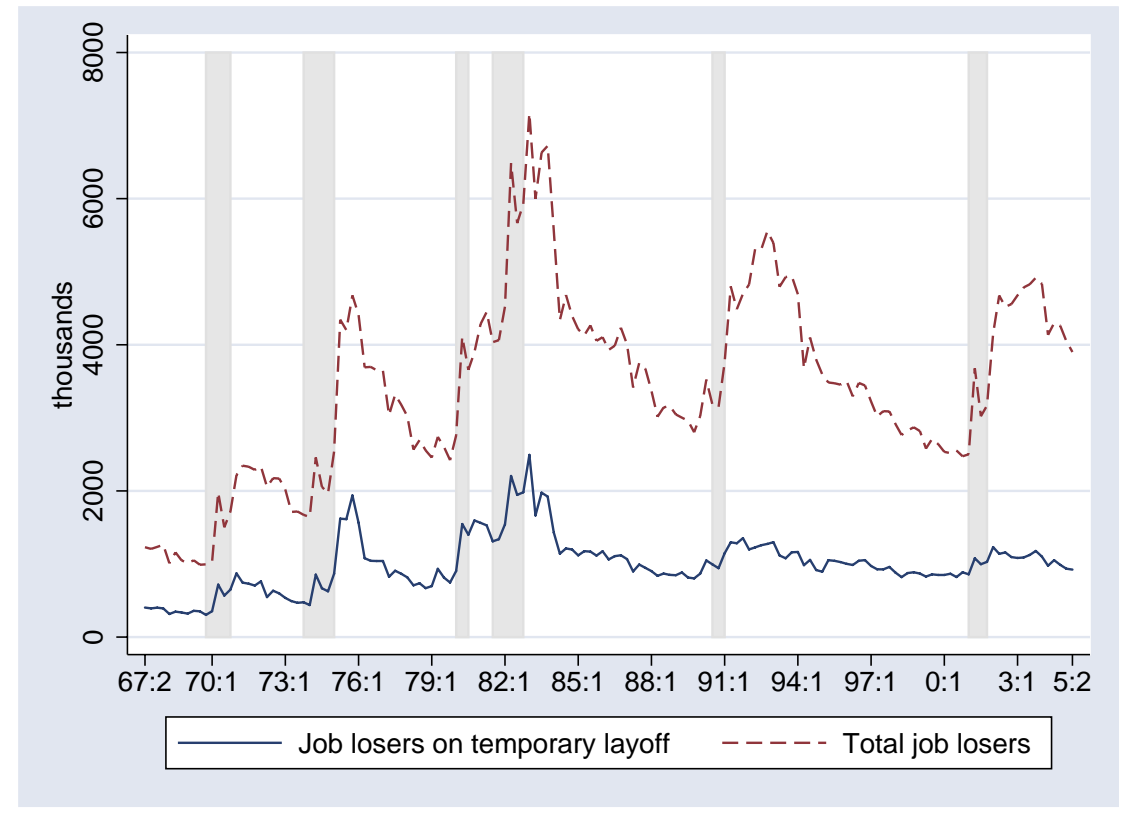

Figure 16: Unemployed Persons by Reason, 1967-2005

There is however a dimension along which this labor-hoarding story does not appear able to explain the facts. According to the evidence on temporary layoffs just discussed, before 1975 the cyclical volatility of skilled labor should have been small relative to the volatility of unskilled labor and GDP. This is because of labor hoarding of skilled workers by firms facing temporary business cycle shocks - as evidenced by the importance of temporary layoffs in the 1969-70 and 1973-75 recessions. The evidence of Section 6 does not support this hypothesis however, as skilled labor was as cyclical as unskilled labor before 1975.

\subsection{Adjustment Costs to Skilled Labor and General Purpose Technology}

Aggregate skilled labor might have become more cyclical because new technologies have reduced training costs for skilled workers. Some have argued (see e.g. Bresnahan and Trajtenberg (1995) and Aghion, Howitt, and Violante (2002)) that information technologies are general purpose technologies, in the sense that they have the potential of being widely used and applied in a variety of sectors of the economy. It follows that skilled workers' comparative advantage in using information technologies should translate into a greater transferability of their skills across firms, jobs, and sectors of the economy. This lower specificity of workers' human capital would then entail lower training costs for firms and consequently reduce the extent of labor hoarding in response to cyclical 
fluctuations. Skilled hours would then become more volatile over the business cycle. Moreover, lower adjustment costs for skilled labor should also have implied an increase in separation rates for this group of workers, relative to the unskilled group, since the mid 1980's. A few papers have indeed documented that this has been the case. For example, Rodriguez and Zavodny (2003) analyze data from the Displaced Workers Surveys and document an increase in displacement rates for college educated workers between 1983-87 and 1993-97. Farber (2005) reports a similar trend comparing the 1980's with the 1990-2004 period.

Notice that this evidence is in principle also consistent with the capital-skill complementarity story developed above. According to the latter, a lower degree of complementarity between skilled labor and capital equipment in the 1990's should have made skilled employment at the firm-level more sensitive to aggregate as well as idiosyncratic shocks. In turn, this higher sensitivity would translate into higher cyclical and average separation rates for skilled workers.

The identification problem between these two competing theories can again be partially resolved by considering the pre-1975 period. According to the capital-skill complementarity hypothesis we have developed, skilled labor should have been as volatile as unskilled labor over the business cycle before the introduction of information technologies. According to the general purpose technology story, instead, skilled labor should have been less volatile than unskilled labor even before 1975. This is because, before the information technology revolution, technologies were such that the human capital of skilled workers was more "specific" to a particular employer and therefore harder to transfer across jobs. Also in this case, the evidence of Section 6 does not support the latter hypothesis.

\subsection{Changes in Taxes}

The US has experienced significant tax cuts in 1981 and 1986. These tax reforms also featured a marked reduction in tax progressivity. As such, skilled workers were likely to have benefited the most from the tax cuts. A natural question is whether this policy change might have contributed to the increase in the relative volatility of skilled hours.

To address this issue, consider the situation where the economy moves into an expansion period characterized by rising hourly wages. The extent to which skilled workers would be willing to expand their working hours depends on the progressivity of the tax code. If marginal tax rates 
increase steeply with income, one should expect skilled workers to increase their labor supply significantly less than unskilled workers. As the tax code becomes less progressive, skilled workers should be willing to expand their labor supply relatively more. Thus, in principle, a reduction in the progressivity of tax rates might account for Stylized Fact \#1. ${ }^{52}$ This mechanism, while plausible, runs into two problems. First, as mentioned above, it is not clear how it could account for the relatively high volatility of skilled labor in the 1960's and early 1970's. Second, the evidence of Section 2.2 reveals that Stylized Fact \#1 is mainly due to the higher cyclical volatility of skilled employment rather than of average hours worked by employed individuals. It is an open question whether a decrease in the progressivity of the tax code would be able to explain the higher volatility of skilled employment.

In conclusion, the purpose of this section has been to discuss some alternative explanations for the higher volatility of skilled labor to the one we have explored in this paper. While these explanations possibly deserve further scrutiny, our discussion has emphasized that, at best, they are not consistent with the non-linear pattern followed by the cyclical volatility of skilled labor during the last 40 years or so. Nevertheless, explanations stressing the decrease in the effective cost of adjusting skilled hours, like the first two, could be complementary to ours in accounting for the sharp increase in the relative volatility of skilled hours.

\section{Summary}

Economists have devoted considerable attention in recent years to documenting and analyzing the increased inequality between skilled and unskilled workers. The focus of the literature has been on the low-frequency increase of the college premium. In this paper, we have studied another dimension along which skilled and unskilled workers are traditionally thought to differ: the sensitivity of their employment status to the business cycle. The data suggest that, while wage inequality between skilled and unskilled workers has been increasing over the last 25 years, inequality among these two groups, as measured by the sensitivity of their employment status to business cycles, is instead lower now than it was 20 years ago. Rather than viewing the low and the high-frequency dynamics

\footnotetext{
${ }^{52}$ Notice that while the mechanisms reviewed in Sections 7.1 and 7.2 operate on labor demand, this one relies on cyclical variations in the relative labor supply of skilled workers.
} 
of inequality as separate phenomena, our hypothesis is that the technological factors responsible for the long-run evolution of wage inequality also help us to understand the short-run dynamics of skilled and unskilled labor.

Using high-frequency CPS data for the period 1979:1-2003:4, we have documented a dramatic increase in the cyclical volatility of aggregate skilled hours relative to GDP, starting from the mid-1980's. Aggregate skilled hours display little cyclicality in the 1980 and 1981-82 recessions relative to unskilled hours and GDP. Starting from the mid-1980's, instead, aggregate skilled hours become more volatile than both unskilled hours and GDP. We have evaluated the extent to which a simple supply/demand model for skilled and unskilled labor based on the hypothesis of capitalskill complementarity in production can help explain these stylized facts. In particular, within this framework, we have considered the impact of the following three effects on the relative volatility of skilled hours: a reduction in the absolute volatility of GDP and unskilled hours since 1984, an increase in the level of capital equipment relative to skilled labor over the sample period, a reduction in the degree of capital-skill complementarity since the late 1980's. We have provided empirical evidence in support of each of these effects. These three mechanisms can jointly explain about sixty percent of the observed increase in the relative volatility of skilled labor, with the reduction in the degree of capital-skill complementarity playing the key role quantitatively. 


\section{A Additional Information Regarding the Data}

In this appendix we provide some additional information regarding the steps followed to construct the variables used in the paper.

\section{Sample Selection}

For each quarter, we restrict attention to individuals in the labor force that are not self-employed to concentrate on paid earnings. For individuals reporting to be employed, we use the following sample selection criteria:

1. Eliminate those with either missing or zero reported earnings.

2. Assign actual hours worked last week to usual hours, if usual hours is missing. This addresses the fact that individuals reporting "hours vary" are declared as having missing usual hours (but not actual hours) after 1993, causing a slight discontinuity in the series for hours between 1993:4 and 1994:1. In fact, it turns out that this imputation of usual hours is applicable only after 1994 .

3. Eliminate those with either zero or a missing value for actual hours, and similarly for usual hours.

\section{Demographic Groups}

We partition the sample into 240 demographic groups in a way analogous to Katz and Murphy (1992) and, more recently, Krusell, Ohanian, Ríos-Rull, and Violante (2000). First, each individual is either male or female. Second, starting from age 16, we create 10 five-year age groups. Third, we consider three race groups, whites, blacks, and otherwise. Last, we create four education groups, (1) no high school diploma (less than 12 years of completed schooling), (2) high school graduate (12 years of completed schooling), (3) some college (between 13 and 15 years of completed schooling) and (4) college graduate and more (16 years of completed schooling and above). After 1992, consistently with the CPS education classification change from years of schooling to educational categories, education group (1) corresponds to less than a high school diploma, (2) to a high school 
diploma, (3) to more than a high school degree but less than a B.A., and (4) to a B.A. degree or higher. This adjustment produces time-series for the number of individuals in each education group, as well as for the various variables of interest, that display no significant break in 1992 .

In defining skill groups, we assign education groups (1)-(3) to the unskilled category and education group (4) to the skilled category.

\section{Efficiency Units and Wages}

A primary reason for recording demographic variables is to allow us to compute adjusted measures of the aggregate labor input, in which actual hours are weighted by some time-invariant base wage rate. This produces series for the labor input in efficiency units, which is more sensible for aggregation across demographic groups. We again proceed in a way analogous to Katz and Murphy (1992) and Krusell, Ohanian, Ríos-Rull, and Violante (2000). ${ }^{53}$

First, for each quarter and for each demographic group in our partition we compute, for employed individuals, (i) the average hourly wage rate, (ii) the average weekly working hours, and (iii) the demographic group's weight in the population. Formally, and using Krusell, Ohanian, RíosRull, and Violante (2000)'s notation, let $G$ be our population partition, where each demographic group is indexed by $g$. We compute:

$$
\begin{aligned}
h_{g, t} & =\frac{\sum_{i \in g} \mu_{i, t} h_{i, t}}{\sum_{i \in g} \mu_{i, t}} \\
w_{g, t} & =\frac{\sum_{i \in g} \mu_{i, t}\left(w_{i, t} h_{i, t}\right)}{\sum_{i \in g} \mu_{i, t} h_{i, t}} \\
\mu_{g, t} & =\sum_{i \in g} \mu_{i, t},
\end{aligned}
$$

where $w_{i, t}$ and $h_{i, t}$ are, respectively, the individual's real hourly wage and usual weekly hours, and $\mu_{i, t}$ is the individual's population weight.

Following Kydland and Prescott (1993), we select the time average of the wage rates over the

\footnotetext{
${ }^{53}$ It may be useful at this point to relate our approach to that of Bowlus, Liu, and Robinson (2002). These authors propose a methodology for constructing labor input series in efficiency units which is based upon a human capital production function with time-varying productivity parameters. Our approach, instead, implicitly assumes no technological progress (the $\beta$ 's in Bowlus, Liu, and Robinson's (2002) notation are constant). In reality, however, since our analysis filters out low frequency movements in the data, it is in fact consistent with long-run technical change.
} 
whole sample as the weights to be placed on hours. ${ }^{54}$ Denoting these weights by $\bar{w}_{g}$, for $g \in G$, we compute the average labor input for a particular population category $j \in G_{j}$ as:

$$
N_{j, t}=\sum_{g \in G_{j}} \mu_{g, t} \bar{w}_{g} h_{g, t}
$$

Depending on the question being asked in the main body of the paper, $G_{j}$ may correspond, for instance, to skilled individuals, or to skilled individuals working in a particular sector, or having a certain occupation.

Similarly, the average wage rate for subgroup $G_{j}$ is computed as the ratio between total weekly earnings and adjusted weekly hours:

$$
W_{j, t}=\frac{\sum_{g \in G_{j}} \mu_{g, t} w_{g, t} h_{g, t}}{N_{j, t}} .
$$

This provides a real hourly wage rate per unit of efficiency supplied by group $j$ individuals. ${ }^{55}$

\section{Sectors and Occupations}

For the analysis by sector of activity, we use the NBER-created 2-digit industry codes (variable "dind") and assign them to the 1-digit 1987 SIC categories (with manufacturing split into durable and non-durable manufacturing).

For the analysis by occupation, one major difficulty is that our data does not provide a timeconsistent occupational classification. Until 1982 it is based on the 1970 Census, but from 1983 until 2002 it is based on the 1980 Census. We developed an assignment between 2-digit occupational codes (and when necessary 3-digit codes) and 1-digit codes. Using this assignment, we do not observe any break in the number of people in each occupational category from 1982 to 1983 . The assignment rule is available upon request.

\footnotetext{
${ }^{54}$ We note that, since some demographic groups have no observations in some quarters, the number of observations used to compute average wages may differ from group to group. Also, similar results obtain if the weights were based on any particular base-period wages.

${ }^{55}$ Our analysis implicitly assumes two separate markets for skilled and unskilled workers, each type earning a different wage per efficiency unit of labor supplied.
} 


\begin{tabular}{ll|ccc|ccc} 
& \multicolumn{4}{c}{ Relative volatility } & \multicolumn{2}{c}{ Comovement } \\
\cline { 2 - 7 } & Variable & skilled & unskilled & aggregate & skilled & unskilled & aggregate \\
\hline 1976:1-1983:4 & Employment & 0.82 & 1.11 & 1.02 & 0.26 & $0.86^{a}$ & $0.87^{a}$ \\
\hline 1984:1-2002:4 & Employment & 1.40 & 0.95 & 0.91 & $0.55^{a}$ & $0.77^{a}$ & $0.82^{a}$ \\
\hline
\end{tabular}

Notes: $a, b, c$ denote correlations significant at 1,5 , and 10 percent level respectively.

Table 12: Volatility and co-movement of total hours, employment and average weekly hours per skill group: Canadian Labour Force Survey

\section{B Canadian Data}

Using Canadian household survey data from the Labour Force Survey (LFS) we have constructed time series of employment for the period 1976:1-2002:4. For simplicity, in this case we just focus on employment since most of the cyclical variation in total hours can be attributed to this margin. To construct these times series, we applied the same sample selection criterion used for the CPS. We focused on individuals aged between 15 and 64 years that reported to be employed and at work, as either private or public employees. Skilled individuals are those classified by the LFS as having a university degree before 1990, and those classified as being university graduates after 1990. This difference reflects a change in the educational classification that was implemented by the LFS starting in 1990. Unfortunately, the post-1990 classification is more restrictive (excludes university certificates), and this induces an artificial drop in the number of skilled individuals from December 1989 to January 1990. We dealt with this issue by applying a constant multiplicative adjustment factor to the whole pre-1990 series such that the number of skilled employed in December 1989 equalled the one in January 1990. The workers in excess were added to the unskilled series before 1990. The raw series were aggregated by quarters, and deseasonalized and noise-filtered as described in the beginning of Section 2.2.

Table 12 presents the cyclical properties of employment in Canada for the pre and post 1984:1 sub-samples.

These results reveal a dramatic increase in the volatility and comovement of aggregate employment for college educated workers in Canada after 1984. The cyclical properties of unskilled employment, instead, remain roughly constant in the two sub-periods. This is the same pattern found in the CPS data. ${ }^{56}$

\footnotetext{
${ }^{56}$ One noteworthy difference between the statistics of Table 12 and those of Table 1 is that, differently from the
} 


\section{References}

Acemoglu, D. (2002): "Technical Change, Inequality, and the Labor Market," Journal of Economic Literature, 40, 7-72.

Aghion, P., P. Howitt, and G. Violante (2002): "General Purpose Technology and Wage Inequality," Journal of Economic Growth, 7(4), 315-345.

Autor, D. H., L. F. Katz, and A. B. Krueger (1998): "Computing Inequality: Have Computers Changed the Labor Market?," Quarterly Journal of Economics, 113(4), 1169-1213.

Beaudry, P., And D. A. Green (2002): "Changes in US wages 1976-2000: Ongoing Skill Bias or Major Technological Change?," University of British Columbia.

Bils, M. J. (1985): "Real Wages over the Business Cycle: Evidence from Panel Data," Journal of Political Economy, 93(4), 666-689.

Blanchard, O. J. (2003): Macroeconomics. Prentice Hall, third edn.

Bleakley, H., A. E. Ferris, and J. C. Fuhrer (1999): "New Data on Worker Flows During Business Cycles," New England Economic Review, (Jul), 49-76.

Bowlus, A., H. Liu, And C. Robinson (2002): "Business Cycle Models, Aggregation, and Real Wage Cyclicality," Journal of Labor Economics, 20(2), 308-335.

Bresnahan, T. F., and M. Trajtenberg (1995): "General purpose technologies 'Engines of growth'?," Journal of Econometrics, 65(1), 83-108.

Card, D., and J. E. DiNardo (2002): "Skill-Biased Technological Change and Rising Wage Inequality: Some Problems and Puzzles," Journal of Labor Economics, 20(4), 733-783.

Chang, Y. (2000): "Wages, business cycles, and comparative advantage," Journal of Monetary Economics, 46(1), 143-171.

Cummins, J. G., and G. L. Violante (2002): "Investment-Specific Technical Change in the United States (1947-2000): Measurement and Macroeconomic Consequences," Review of Economic Dynamics, 5(2), 243-284.

U.S., the relative volatility of skilled employment in Canada is closer to that of unskilled employment before 1984 . 
Fallon, P. R., and P. R. G. Layard (1975): "Capital-Skill Complementarity, Income Distribution and Output Accouting," Journal of Political Economy, 83(2), 279-302.

FArber, H. S. (2005): "What do we know about Job Loss in the United States? Evidence from the Displaced Workers Survey, 1984-2004," Princeton University, Industrial Relations Section, Working Paper \# 498.

Gordon, R. J. (1990): The Measurement of Durable Goods Prices. University of Chicago Press, Chicago, IL.

Greenwood, J., And M. Yorokoglu (1997): "1974," Carnegie-Rochester Conference Series on Public Policy, 46, 49-95.

Hansen, G. D. (1985): "Indivisible Labor and the Business Cycle," Journal of Monetary Economics, 16, 309-327.

(1993): "The Cyclical and Secular Behaviour of the Labour Input: Comparing Efficiency Units and Hours Worked," Journal of Applied Econometrics, 8, 71-80.

KATZ, L. F. (1999): "Technological Change, Computerization, and the Wage Structure," Harvard University.

Katz, L. F., And K. M. Murphy (1992): "Changes in Relative Wages, 1963-1987: Supply and Demand Factors," Quarterly Journal of Economics, 107(1), 35-78.

Keane, M. P., And E. S. Prasad (1993): "The relation between skill levels and the cyclical variability of employment, hours and wages," Working paper 93/44, International Monetary Fund.

Kocherlakota, N. R. (1996): “The Equity Premium: It's Still a Puzzle," Journal of Economic Literature, 34(1), 42-71.

Krueger, A. B. (2002): "As recovery builds, the less educated go to the end of the employment line," New York Times, March 7.

Krugman, P. (1996): "White Collars Turn Blue," New York Times, September 29. 
Krusell, P., L. Ohanian, J.-V. Ríos-Rull, and G. L. Violante (2000): "Capital-skill complementarity and inequality: a macroeconomic analysis," Econometrica, 68(5), 1029-1053.

Kydland, F. E. (1984): "Labor-Force Heterogeneity and the Business Cycle," Carnegie Rochester Conference Series on Public Policy, 21, 173-208.

Kydland, F. E., and E. C. Prescott (1993): "Cyclical movements of the labor input and its implicit real wage," Federal Reserve Bank of Cleveland Economic Review, 29(2), 12-23.

Lindquist, M. (2004): "Capital-Skill Complementarity and Inequality over the Business Cycle," Review of Economic Dynamics, 7(3), 519-540.

McConnell, M. M., And G. Perez-Quiros (2000): "Output Fluctuations in the United States: What Has Changed Since the Early 1980's?," American Economic Review, 90(5), 1464-1476.

Nelson, R. R., And E. S. Phelps (1966): "Investment in Humans, Technology Diffusion and Economic Growth," American Economic Review Papers and Proceedings, 56(2), 69-75.

OI, W. (1962): "Labor as a Quasi-Fixed Factor," Journal of Political Economy, 70, 538-555.

Prasad, E. (1996): "Skill Heterogeneity and the Business Cycle," Canadian Journal of Economics, 29(4), 910-929.

Prescott, E. C. (2004): "Why Do Americans Work So Much More than Europeans?," Quarterly Review, 28(1), 2-13.

Ravn, M., And H. Uhlig (2002): "On Adjusting the HP-Filter for the Frequency of Observations," Review of Economics and Statistics, 84(2), 371-376.

Reder, M. W. (1955): "The Theory of Occupational Wage Differentials," American Economic Review, 45(5), 833-852.

Rodriguez, D., And M. Zavodny (2003): "Changes in the Age and Education Profile of Displacement," Industrial and Labor Relations Review, 56, 498-510.

Rogerson, R. (1988): "Indivisible Labor, Lotteries and Equilibrium," Journal of Monetary Economics, 21(1), 3-16. 
Rosen, S. (1968): "Short-Run Employment Variation on Class-I Railroads in the U.S., 1947-1963," Econometrica, 36(3/4), 511-529.

Solon, G., R. Barski, and J. A. Parker (1994): "Measuring the cyclicality of real wages: how important is composition bias?," Quarterly Journal of Economics, 109(1), 1-25.

Stock, J. H., and M. W. Watson (2002): "Has the Business Cycle Changed and Why?," in NBER Macroeconomics Annual, pp. 159-218. National Bureau of Economic Research, MITPress.

Young, E. R. (2003): "The Wage Premium: A Puzzle,” Florida State University. 